Portland State University

PDXScholar

Winter 3-11-2016

\title{
Growing STEM Education on the Playground: A Case Study of the Factors That Influence Teachers' Use of School Gardens
}

Megan Poole

Portland State University

Follow this and additional works at: https://pdxscholar.library.pdx.edu/open_access_etds

Part of the Educational Methods Commons, Elementary Education and Teaching Commons, and the Science and Mathematics Education Commons

Let us know how access to this document benefits you.

\section{Recommended Citation}

Poole, Megan, "Growing STEM Education on the Playground: A Case Study of the Factors That Influence Teachers' Use of School Gardens" (2016). Dissertations and Theses. Paper 2723.

https://doi.org/10.15760/etd.2719

This Thesis is brought to you for free and open access. It has been accepted for inclusion in Dissertations and Theses by an authorized administrator of PDXScholar. Please contact us if we can make this document more accessible: pdxscholar@pdx.edu. 
Growing STEM Education on the Playground:

A Case Study of the Factors That Influence Teachers' Use of School Gardens

\author{
by \\ Megan Poole
}

A thesis submitted in partial fulfillment of the requirements for the degree of

Master of Science in Teaching

in

General Science

Thesis Committee:

William Becker, Chair

Sybil Kelley

Stephanie Wagner

Portland State University

2016 


\begin{abstract}
School gardens can have a profound, positive influence on a student's academic achievement, social skills, and attitudinal orientation. Despite these clear benefits, the use of school gardens as an instructional medium is not as prevalent as would be expected. There are several types of obstacles that can prevent teachers from using school gardens, including facets of time, support, and knowledge-based challenges. This multiple case study employs a mixed methods design to uncover factors that influence primary school teachers' decisions to utilize a school garden in their STEM curriculum. The goals of this study were to determine the types of benefits and barriers primary school teachers encountered in the study school district. All of the teacher participants worked within the same school district, had access to established school gardens on their campus, and were supported in their instruction and use of materials by the district's Science and Technology Center (STC). Quantitative data was collected from garden resource and teacher self-efficacy surveys; qualitative data about teacher rationales was extracted from in-depth teacher interviews. Overall analyses determined that aspects of instruction and logistics were the most important factors for a teacher to have in her decision to utilize her school garden. These data are presented and discussed in the context of identifying trends in teachers' use of school gardens as instructional tools so that actions might be taken to remove barriers and increase curriculum opportunities.
\end{abstract}




\section{Acknowledgements}

It goes without saying that no research is conducted single-handedly. Without the incredible support I have received from so many people throughout this academic process, what you are about to read would be a mess of data points and incomprehensible conjectures. That being said, I'll start by thanking my thesis committee. Stephanie Wagner was my original “cheerleader” for the Master's in Science Teaching program, and that did not change once I started the program and the rubber hit the road. She is a bottomless source of encouragement and ideas. I read one of Sybil Kelley's papers early in my research process and was inspired by her ability to weave a rich representation of qualitative and quantitative data together. Her expertise in garden-based curriculum has obviously been incredibly helpful to this research process. William (Bill) Becker structured my initial introduction in the history of science teaching and did so in a way that made me want to contribute to that history.

Working at the Center for Research in Environmental Sciences and Technologies (CREST) has truly been a wonderful experience that has been incredibly valuable on more levels than I have fingers with which to count. The commitment that the team there has to students is something I've rarely seen, and has far-reaching positive impacts on the students and community. The director of CREST, Bob Carlson, has been incredibly helpful, supportive, insightful, and impactful with everything about this project, and to my own teaching and learning philosophies.

The teachers who so graciously and unquestionably offered to help me with my research were an incredible bunch of people that I feel so fortunate to have been able to 
work with and learn from. They embodied the teacher who would do anything if it meant her students benefitted and grew as a result. Every interaction I had with these teachers was positive and taught me something valuable.

The six other students in my MST cohort provided endless shoulders to lean on, constructive criticism, and jokes when things got too serious. I can't imagine a more unique or perfectly paired cohort to go through a program with, and am so grateful for their candor and support.

Melissa Potter and Cary Sneider provided what felt like endless hours of question answering, worry assuaging, and nudges in the right direction. I have learned so much from both of them professionally and personally as far as how to support and encourage students that I've literally had to start writing it down... it covers a great many pages.

Throughout the course of this MST program, I have come to realize how truly phenomenal many of my previous teachers have been. It is their dedication and creativity that inspired me in the first place, and guided my inquiry forward.

My family, of course, has supported me from day one when I didn't even know the words for "science" or "teaching", and for that I will never find an appropriate way to express the magnitude of my gratitude. They've been there when I needed pep talks and when I needed some constructive "redirection", but have never wavered in their cheering volume. 


\section{Table of Contents}

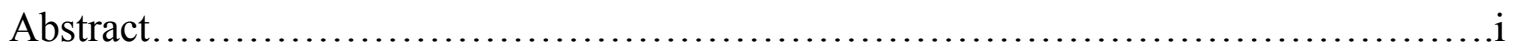

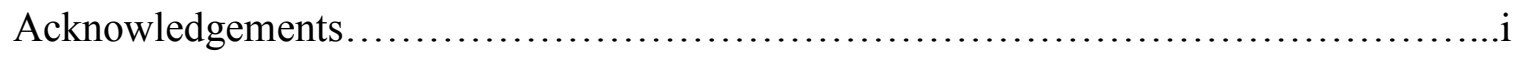
i

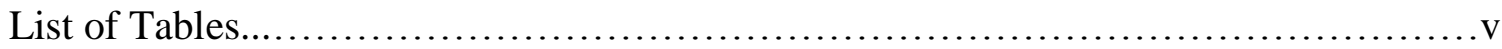

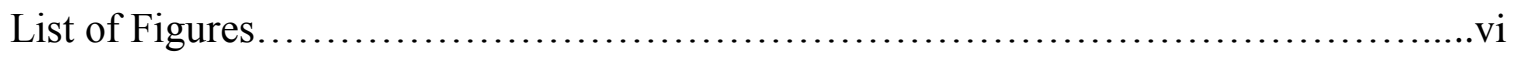

Chapter 1

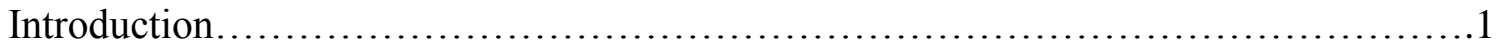

Chapter 2

Literature Review.......................................................... 10

Chapter 3

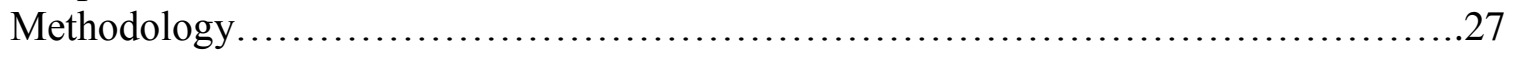

Chapter 4

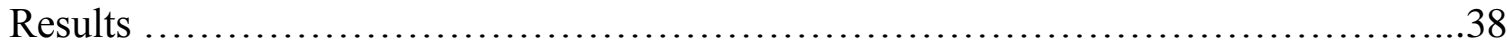

Chapter 5

Discussion .............................................................55

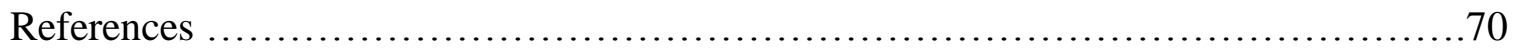

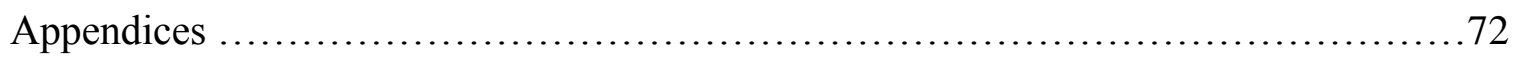

A. IRB Approval 


\section{List of Tables}

Table 1- School demographic data from 2013-2014 school year...................28

Table 2- Participating Teacher Descriptions................................... 39

Table 3- Average Ranking When Rated by Two or More Teachers...................42

Table 4- Teacher interview responses summary...............................48

Table 5- Perceived student benefits of using the school garden....................50

Table 6- Perceived barriers to teachers when using the school garden................51 


\section{List of Figures}

Figure 1- Photograph of a high-use garden within the Lakeridge District...............30

Figure 2- Photograph of a low-use garden within the Lakeridge District................30

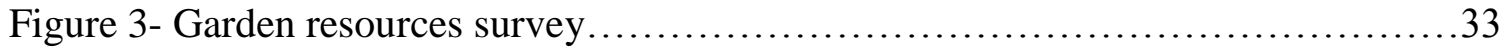

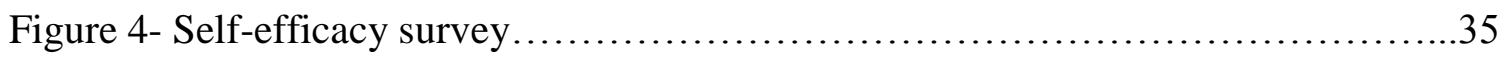

Figure 5- Interview Questions................................................. 36

Figure 6- Number of Times Factor Included in Overall Rating........................41 


\section{Introduction}

A school garden can be a powerful learning medium that is beneficial and worthwhile for both teachers and students. It can ground children in the immediacy of many processes and cycles that are essential to a child's own growth and health. Gardens are environments full of complexity in which children's cognitive capabilities have the opportunity to expand (Blair, 2009). Gardening can provide authentic experiences that contribute to student understanding of a range of topics within a standard curriculum; as one researcher put it, "school grounds are an ideal teaching lab that can provide more learning space at a very low cost” (DeMarco, Relf, \& McDaniel, 1999, pg. 5). School gardens are often touted as optimal settings for authentic, inquiry-based, hands on learning (Klemmer, Waliczek, \& Zajicek, 2005) which have been shown to be effective at increasing cognitive abilities and higher order thinking skills (A Framework for K-12 Science Education, 2013). Furthermore, school gardens are a rich resource for teaching STEM (science, technology, engineering, and math) topics due to their hands-on nature and have been found to produce positive changes in other academic subjects as well. They have even been shown to perceptibly affect a variety of life skills in children, from food habits to social development to attitudinal changes toward environment (D. R. Williams, 2012). When lessons are in line with teachers' goals for student learning, teachers often remark that gardens are an interactive tool and a good way to get kids outside and using their imaginations (Jorgenson, 2014).

The concept of school gardens started to gain traction in the United States in the 1990s. One of the original, and now one of the most influential, school garden programs 
is the Edible Schoolyard Project in Berkeley, California (The Edible Schoolyard Project, n.d.). It all started when a journalist and a chef were discussing the chef's daily walk to work that took her by the schoolyard near her house. She was frustrated by the fact that it looked tired, like nobody cared about it. Not long after the article ran, the principal of the school contacted her and enlisted her help in finding a solution. That conversation quickly bloomed into an idea for a school garden where students could learn about food: how to grow it with science, how to plan it with math, and even how to use it to study history. The opportunities for teaching and learning seemed too good for the teachers, principal, parents, students, and of course the chef to pass up. The Edible Schoolyard Project has now been around for twenty years and served over 7,000 students. The program has approximately 1,000 visitors annually who come from local neighborhoods and the far reaches of the globe alike to learn about the program and its impacts.

Today there are many similar projects underway throughout the United States including Learning Gardens Laboratory in Portland, Oregon; Life Labs in Santa Cruz, California; the Boston Schoolyard Initiative in Boston, Massachusetts; Cornell GardenBased Learning in Ithaca, New York; Common Roots in South Burlington, Vermont; and The Garden Initiative in Chicago, Illinois. All of these programs are living, breathing examples of how school gardens can serve many purposes within a school setting and how learning in a garden environment can directly benefit students in a variety of ways.

The setting of this research study is the primary school gardens within the Lakeridge (pseudonym) public school district near Portland, Oregon. This K-12 public school district includes two towns and serves approximately 8,400 students between their 
nine primary schools, three middle schools, and two high schools, as well as an arts and technology-focused high school. What makes it rather unique is that all nine of the primary schools in the district have an established school garden on-site. Some schools utilize their garden a great deal, others haven't planted in their garden for years (see Table 1). Another unique factor is that all of the schools are supported by the district's Science and Technology Center (STC). The STC has a thirteen-year history within the district, and is well-known and loved by teachers and students.

As part of my research with the STC, I helped to organize and teach an earlySpring garden lesson in each second grade classroom within the district. I also received instructional guidance and support from the director of the STC in order to provide meaningful learning experiences in the gardens. As a result of this program immersion, I had the opportunity to be directly involved in the interplay of garden-based learning theory and real world practice, opening up an excellent opportunity for a case study. The possibilities for curriculum connections by way of a garden seem bountiful, and gardening can be an enriching, memorable, and impactful experience... but it can also look like a bunch of kids pulling weeds and throwing dirt at each other. There has to be a method to the madness, and that method is not always inherently obvious or easy to implement- even for a teacher with many years of experience and expansive garden knowledge. Finding out how to make this opportunity a more realistic option for teachers is the first step in getting students' hands dirty.

It's reasonable to assume that if a teacher doesn't have access to essentials for gardening, like space, shovels, and seeds, it will be nearly impossible for her to 
effectively incorporate a garden into her curriculum regardless of other factors (DeMarco et al., 1999). Funding is often a huge choke weed for a school garden, as gardening supplies can be expensive and numerous. Finding room in the budget for a class set of shovels and a load of compost often has a lower priority level than funding for books and other classroom supplies. Even soliciting donations from parents or the community is a big responsibility for someone to take on. There is also the time commitment to consider, and weeding and watering can seem like too great of a challenge to be worth the reward. Other logistical considerations such as amount of time for meaningful instruction within a school day likely factor in as well (Graham \& Zidenberg-Cherr, 2005). It costs time for a class to shift from a classroom to a garden and regain lesson focus and purpose. It also takes time to create/adapt, and prepare/organize focused lessons plans for use in a garden. Additionally, less tangible influences like principal, district, or fellow faculty's support of learning in a garden are often important factors in a teacher's decision. Some do not see a garden as an opportunity to add significant value in place of a traditional classroom lesson. It may be hard to justify spending time learning fractions by dividing a garden bed vs. exploring symbols on a white board. Descriptive studies indicate that many teachers are more likely to include a garden in classroom instruction if administrators work to solve these types of external barriers (DeMarco et al., 1999). I would interpret that to mean that one of the biggest obstacles for teachers to overcome in a school garden setting is access to resources and support.

Once these external factors are taken into account, it's important to also consider internal factors. A teacher will be more successful in his garden use if he is familiar with 
how to incorporate it so that the time in the garden isn't wasted by confusion or unclear expectations. The methods for teaching students about multiplication and averages by calculating tomato yield are entirely different than those for analyzing word problems in a textbook. Students will learn more about math either way, but the delivery and practices of the teacher must change considerably from one method to the other.

There is an art and skill to being able to engender student comprehension in either case, and successful teachers are familiar with which practices work and which do not. Effective instructional practices can have a significant influence over students' abilities to problem-solve and break through learning barriers (Anderson \& Clark, 2011). However, a teacher may see significant challenges in developing or adapting his knowledge toward effective garden-based instruction because of the different qualities between a traditional classroom and an outdoor setting (Dyment, 2005). Furthermore, a teacher may think that because he knows nothing about growing plants that he should avoid using the garden for STEM-based lessons. In reality, using a garden as a teaching medium doesn't require a masterful ability to grow plants, only the ability to expose students to an environment where they get to interact with what they are learning about. Sometimes this hesitation on a teacher's part is due to his overall confidence in leading instruction in an environment or subject area that is either unfamiliar or unpredictable.

Individual instructional decisions based on teacher confidence is perhaps one of the trickiest challenges to solve because it is rooted in years of individual experiences and perceptions. This construct, in this context also known as self-efficacy, has been defined by psychologist Albert Bandura as one's belief in one's ability to succeed in specific 
situations (Tschannen - Moran \& Hoy, 2002). According to Bandura, those with high levels of self-efficacy view difficult tasks as challenges to be mastered rather than subjects to be avoided. The opposite is often the case for those with low self-efficacy. It depends on a variety of factors including a teacher's practical knowledge, her previous experience with the subject (or teaching of the subject), and her confidence in her level of SMK (Tschannen - Moran \& Hoy, 2002). Self-efficacy can affect a teacher's ability to represent certain subjects, their presentation style, and their ability to be a sound resource for student challenges and inquiry. For these reasons, teacher self-efficacy is thought to be the main characteristic that demonstrates a consistent relationship with student achievement (Ramey-Gassert, Shroyer, \& Staver, 1996).

In a school garden setting, there are important differences between self-efficacy for general teaching vs. teaching in a garden vs. general gardening. A teacher may have high confidence in her ability to teach students about plant growth with classroom simulations, but if she lacks confidence in her ability to grow real plants that may be the deciding factor for her class' garden exposure. Primary school teachers- as a gross generality- are less confident in their STEM topic knowledge than secondary school teachers- who tend to specialize in a particular subject (Nadelson et al., 2013). Additionally, gardens are a non-traditional class setting where the tone and discipline of the classroom can be a considerable struggle to recreate (Dyment, 2005). If a teacher is already questioning her ability to effectively teach STEM topics, adding a non-traditional setting to the mix may be overwhelming to consider. While self-efficacy is probably one of the more challenging factors for a teacher to recognize and change, it can be positively 
influenced by a variety of factors, including professional development and external support. Moreover, increasing a teacher's self-efficacy in one area can positively impact her self-efficacy in other areas (Tschannen - Moran \& Hoy, 2002).

There are many factors that a teacher must take into account before she ventures out into the garden with her students. Access to space, shovels, and seeds are all majorly important to many of the kinds of lessons that will take place in a garden. Even if a teacher has these, she may work in a school where the culture doesn't support or see the value in taking students into a school garden. She may also have very good methodologies for teaching her students in the classroom, which may be completely different from how they could feasibly be taught in a garden setting. Finally, her overall confidence in taking students out into the garden may fracture under the challenge of teaching in a non-traditional classroom setting. Despite the finding that using a garden as an instructional medium has been shown to be beneficial to student learning, it isn't inherently easily incorporated into a school day.

The purpose of this research is to gain a better understanding of those barriers that may give a teacher pause. The focus of this case study was to gather in-depth feedback from teachers on their garden use and the reasoning behind it. My hypothesis was that the main factors that create barriers for teachers are based in the teacher's individual knowledge, be it STEM- or gardening- specific. The hierarchy of importance and exact origins of each factor remain to be discovered.

In order to structure the research and open up broader opportunities to learn about as-yet-unidentified factors, I examined teachers' garden resources by employing a mixed- 
methods, case study approach. I used teacher responses in surveys and interviews for my primary data sources. First, to learn more about garden resources, I surveyed teachers using an adapted resource from a paper by Demarco, Relf, and McDaniel (1999), which outlines a comprehensive list of many of the physical factors that are important to using a school garden in the first place. I also administered a Self-Efficacy Survey adapted by the Portland Metro STEM Partnership (Saxton et al., 2013), (Tschannen-Moran \& Hoy, 2002). Quantitative data from this instrument provided information on different teachers' levels of confidence in their capabilities with regard to teaching STEM topics. Finally, I interviewed teachers to learn more information about their experience when it comes to using a learning medium like school gardens to effectively teach these concepts.

Arguably, students will remember topics better and be able to apply their knowledge in novel situations more effectively if they learn in a hands-on, activity-based fashion as they would in a garden (D. Williams \& Dixon, 2013), (Flick, 1993). That is not to say that teaching by other means, including with paper and pencil, are not also effective. For the purposes of my research study, "effective use" is considered accomplished when a teacher claimed she was able to utilize the garden space for the setting of STEM-based lesson and her academic goals for students were met.

The immediate context of this data provides insight into how to best support elementary school teachers who want to utilize their school gardens within the Lakeridge school district. The broader fields that this information may influence are teachers, teaching teams, principals, or other school district leaders who are interested in learning how to create or better support their own school garden programs. School gardens 
provide students with many diverse opportunities that enrich their learning experience and academic achievement. Learning more about how to identify and remove teacher barriers in the context of a school garden is an important first step. 


\section{Literature Review}

The following literature review is a summary of articles outlining research experiments, theory of practice, and interview-based inquiries related to school gardens. The first section is a general outline of what school gardens are, their effects on student learning, and how they can be used as a cross-disciplinary teaching tool. The final section includes research findings and theory summaries outlining how a teacher's selfefficacy affects students and could in turn be a deciding factor in the use of a school garden to supplement STEM learning for students. These elements are a part of a teacher's everyday considerations regardless of learning setting. However, this review will provide a background for how these specific factors may influence a teacher's decision to use a school garden setting for instruction.

\section{How does your garden grow?}

Can a school garden could have a measurable impact on student achievement and behavior? Based on her review of publications ranging from case studies to large-scale experiments, Dorothy Blair argued that the integration of gardens into curricula has been shown to have a positive impact on improving children's enthusiasm for school and learning, standardized test scores, and GPAs (Blair, 2009). Multiple studies demonstrate how gardens naturally teach children about ecological complexity and foundations they encounter in everyday life. Two reviewed studies in particular showed that hands-on learning in general is effective in stimulating higher order cognition. School gardening increased student science test scores in all twelve of the quantitative studies Blair reviewed. Furthermore, $75 \%$ of the studies found positive learning and behavior effects 
as direct results of gardening. Studies reported: students were positively motivated by working in the garden; school attitude and pride increased; gardens acted as a strong community builder; and gardens provided a variety of education opportunities including math, science, language arts, and environmental education. Blair also reviewed several papers from teacher and district points of view. All of these emphasized the need for dedicated garden coordinators and high-quality professional development opportunities for teachers, but that overall gardens were viewed as effective teaching conduits.

Where Blair's review encompassed very wide array of literature on the effects of school gardens overall, the comprehensive review of school gardens by Dilafruz Williams and P. Scott Dixon focuses primarily on studies demonstrating quantifiable academic effects and indirect effects (i.e. life skills, eating habits) of school gardens. They summarized and analyzed overall results from 152 articles published between 1990 and 2010 concerning school garden programs (D. Williams \& Dixon, 2013). The authors found that overall there is a great deal of evidence to suggest positive impacts on direct academic outcomes as well as indirect outcomes (increased life skills, greater ability to focus, etc.). Through careful evaluation, they found that nearly half of the studies that met their review criteria centered around grades 3-5, while the effects of gardening on grades 10-12 and preschool were studied the least. Of the forty studies that assessed direct learning outcomes, thirty-three found positive effects, one found negative effects, and six indicated no change. Science learning had the highest proportion of positive effects. Positive outcomes were often related to the direct, hands-on experiences that made classroom activities relevant. Social development was the most commonly 
assessed indirect academic outcome and mostly resulted in positive effects on students' development. The main criticism that the authors gathered from their findings was the lack of research vigor of study validity and/or information on study demographics (gender, socio-economic level, race/ethnicity, etc.). Nonetheless, the overall results of these studies indicated strong and frequent positive impacts in all areas studied, both direct and indirect, and across all grade levels.

A garden is a hands-on place where students can use all of their senses and abilities to make observations and solve problems. The term "hands-on" described by Lawrence Flick (Flick, 1993) gives a more concrete definition of hands on instruction as well as its influences. The first definition he uses to encompass this term holds that "students participate significantly in the teaching-learning process as a result of relevant prior knowledge that they use to make meaning of a new experience." The second view revolves around how "students gain new knowledge by associating careful observations with new terms" during hands on activities. He cautions that the term "hands-on" doesn't automatically imply that children understand concepts and content simply because they are actively engaged. Flick notes that younger students especially learn through actions, more so than older students, and therefore experience greater benefits from hands-on and action-oriented learning. This helps more students experience more success in their learning because it is reinforced by multiple senses at once.

School gardens can also have positive impacts on teachers. In an effort to unearth more data about this subject, several researchers (Graham \& Zidenberg-Cherr, 2005) summarized the data they gathered from their survey of teachers who used gardens to 
teach nutrition. They sent this survey to 1,665 fourth-grade teachers throughout California, with questions focusing on how they perceived school gardens as a tool to teach nutrition and if there were additional activities for which teachers may have used the garden. Of the 616 teachers who responded, $47 \%$ utilized the gardens as a tool for teaching nutrition, $65 \%$ used it to teach science, $43 \%$ for environmental studies, $42 \%$ for language arts, $40 \%$ for math, and $27 \%$ for agricultural studies. Teachers generally included feedback that gardens were a great way to tie in nutrition, math, science, and language arts skills to what takes place in the classroom, as well as enhance science and social skills. Teachers strongly agreed that teacher training and linking lessons to standards would assist and enhance the levels of participation by teachers and their classrooms in school gardening programs. The biggest barriers perceived by teachers to utilizing the school garden was time. However other barriers noted were: teacher's overall lack of interest in gardening; lack of experience, knowledge, or training about gardening; and lack of teaching materials linked to the academic standards. Overall, the majority of teachers used the gardens despite any barriers due to their perception of the positive effects working in the garden had on students.

Similarly, in an attempt to find out more about the use of school gardens from a teacher's perspective, Demarco, Relf, \& McDaniel (DeMarco et al., 1999) identified 315 elementary school teachers who were knowledgeable in integrating garden programs into curricula. The researchers then sent the teachers surveys about what resources they needed in order to continue successful school garden programs. Teachers were asked to identify and rate five items (from a list of eighteen) from most to least important on a 
scale of one to five. Each item's rating was symbolic to its importance to sustaining a successful school garden. In addition, twenty-eight of the teachers surveyed were invited to participate in an interview-based study, where they were asked to cluster thirty different items printed on note cards into groups "not important," "important," and "most important" as far as the item's importance to sustaining a school garden program. In both of these cases, teachers were invited to add-in any items they thought merited consideration. Overall, the analyses of the data from the 236 survey responses received showed that teachers valued faculty and student commitment as the number one most important attribute. Availability of physical resources came next and included a site for the garden and funding as the top two physical resources needed. Third most important was faculty knowledge of the application of gardening into the curriculum. Additionally, $91 \%$ of respondents to the survey responded that in order for a garden program to be successful, they felt there must be a leader who took responsibility for the overall state of the garden. Interestingly, teachers considered their knowledge of gardening concepts to be more important than their knowledge of science concepts with regard to successful use of their school garden in a science lesson. The results also indicate that for a teacher to be motivated to use the garden, he or she must be able to recognize it as a valuable teaching tool and see it as a means to justify their academic goals for students. As a result of digging into the overall effects of learning in a school garden setting, several attributes seem to stand out. In her review of research studies involving the effects of school gardens on students, Dorothy Blair (2009) showed that the integration of gardens into curricula has been shown to have a positive impact on 
improving children's enthusiasm for school and learning, standardized test scores, and GPAs. Williams and Dixon (2013) further demonstrated through a comprehensive literature review that school gardens can create strong positive impacts in all areas of student learning and development across all grade levels from social to academic affects. The positive impacts of school gardening for teachers as outlined by Graham \& Zidenberg-Cherr (2005) included teachers feeling that school gardens were a good way to teach multiple subjects in a hands on environment. While the biggest barrier they reported facing in using this teaching medium was time. Finally, the survey conducted by Demarco, et al. revealed that teachers need to see significant value in using the garden as a teaching tool in order to be motivated to use it. What these studies collectively indicate is that learning in school gardens has been shown to create positive results for students and is seen as valuable by teachers. Nonetheless, the studies also demonstrate that there are barriers to using school gardens in instruction and that they must add significant value in order to become part of a teacher's curriculum.

\section{Sowing the Seeds of Content Knowledge}

The previous section outlines that school gardens can benefit student learning, understanding, and problem solving in a variety of subjects and social aspects. Several of the reviews outline teacher perceptions towards utilizing gardens in their own curriculum. But where do teachers get the information to teach with this medium, or about STEM topics in general, if they don't already have a firm background knowledge? Many studies point to effective instructional practices. In the case of garden-based lessons, teachers will approach them from many points along the spectrum of expertise. These aspects can 
often be enhanced by professional development opportunities where teachers learn how to use school gardens for hands-on learning across a variety of curriculum types.

In developing an opportunity to increase both teacher subject matter knowledge and pedagogical content knowledge, researchers Sybil Kelley and Dilafruz Williams examined how a group of thirty K-8 teachers in Portland, Oregon experienced a professional development workshop (Kelley \& Williams, 2013). Students (K-8 teachers) were invited to participate in a summer gardening program, in which the teachers (Kelley and Williams) taught curriculum that the K-8 teachers learned and then themselves taught to kids who participated in the summer gardening program. The researchers asked the teachers to reflect on two questions while they were both learning and teaching: 1) What have you learned about teaching and learning in a garden-based context? 2) How has working with a team of educators shaped your experience? In order to quantitatively assess the biggest impact on teachers in this workshop, Kelley \& Williams clustered the teachers' responses into three overarching categories: experienced and engaged learning, integrated learning, and collaborative professional learning. Based on results from this data and qualitative responses from teacher interviews, the most transformative aspect of the courses was the teachers' opportunity to learn alongside their peers. One teacher noted that it was beneficial for her to participate in this professional development workshop because of the energy of her colleagues and the opportunity to gain ideas and insights from them during the professional development portion. Both the students and the teachers were able to co-construct understandings of topics and big ideas through direct observations of events experienced together. This was especially important for the 
teachers, many of whom relayed that they learned as much from each other as they did from the course instructors. Due to their experience in the professional development workshop, many of the teachers felt they could now be successful in being able to teach lessons based in the school gardens. The authors emphasize that when any learner feels successful, it builds confidence and self-efficacy in addition to knowledge.

Analogously, a group of researchers in Hawaii (Ray, Wei, \& Barrett, 2010) created and implemented a year-long professional development program focused on school learning gardens in order to further educate teachers about how to teach principles of sustainability to their students. Twenty-nine K-12 teachers enrolled in several intensive, week-long courses where they learned about different aspects of garden-based sustainability topics directly from the researchers. Teachers took pre and post workshop surveys specifically developed to measure changes in their own attitudes due to their participation in the program. Statistical analyses of the results showed that after taking the workshops, teachers had significant positive changes in their overall attitudes, views of productivity (ability to teach and assess students), and comfort with teaching about sustainability education through utilization of the school gardens. Ray, et al. concluded that these results are strong evidence to support the idea that well-planned, intentional professional development opportunities can help teachers feel knowledgeable and comfortable in conveying knowledge to students.

In order to teach science effectively, teachers must have a firm subject matter knowledge (SMK) that includes knowledge of science (general topic knowledge like geology or chemistry) and knowledge about science (how we know what we know about 
these topics) (Anderson \& Clark, 2011). Once a teacher has firm foundation for her SMK, the addition of a strong teaching pedagogy (the ability to effectively represent the subject matter) is how the equation works out for student learning and knowledge retention. Teachers teach and assess their students based on their own knowledge levels, so if a teacher's knowledge is not adequate, then her overall ability to guide and teach students will suffer, with direct impacts on students (Anderson \& Clark, 2011). In their study aimed at learning how teachers develop SMK and Kelly and Williams (2013) found that the most transformative aspect of the courses was the teachers' opportunity to learn alongside their peers. Teachers found it most valuable to have the opportunity to coconstruct their SMK through events experienced together. Finally, the results of the study published by Ray, et al. indicates that high quality professional development courses can have positive impact on teachers' knowledge and comfort levels when teaching students. The opportunities for increasing knowledge through professional development revolve around a combination of subject matter and instructional practice training in order to provide a variety of resources for teachers. Those that focus on science teaching or garden knowledge (or both) have been shown to significantly strengthen not only a teacher's knowledge and instructional practices, but her selfefficacy as a transcendent result.

\section{Harvesting the Fruits of all that Labor}

The confidence that a teacher has in her ability to effectively transfer knowledge to her students can tip the scales in either direction with regard to teacher success and student outcomes. It is thought that teacher self-efficacy (confidence) has the biggest 
impact on student learning, when compared to all other teacher qualities (Ramey-Gassert et al., 1996). That said, how does a teacher develop this confidence and how can it potentially change with time or with subject matter? While self-efficacy may also be one of the most difficult things for a teacher to identify and change in her teaching, it is also one of the most impactful.

Another proposed way to foster change in attitudes towards science is to reestablish inquiry foundations and learning processes. Two researchers set out to see how inquiry-based science training would impact pre-service teacher self-efficacy, the idea being to teach science as it is practiced (Avery \& Meyer, 2012). One of the authors taught an Environmental Biology course consisting of 77 students, mostly pre-service teachers. Students designed and carried out experiments, prepared reports, and participated in double blind peer-review of each other's reports. While these experiments were guided, they were often open ended after the instructor demonstrated a technique, requiring students to apply what they had learned to new situations. The authors developed their own instrument for gauging pre and post course self-efficacy, which they coined the ISTEBI (inquiry science teacher efficacy belief instrument) to more adequately focus on the inquiry-based emphasis in this study. What the authors found upon data analysis was puzzling - there was no statistically significant difference in selfefficacy.

Stumped, they did some deeper digging and found that there were two groups that were "cancelling" each other's results. One group, the majority of students, reported lower confidence in science in pre surveys but reported higher confidence in post 
surveys. The other group, the minority, generally reported higher (when compared to the whole class) confidence in science before the course, but by the end of the course reported lower confidence. The authors explanation is that perhaps these students, who typically excelled in traditional, non-inquiry based classrooms, became frustrated by the format of this class and labs. The authors also looked at quantitative data from post course surveys. They found that overall students reported: a more positive attitude toward science, an increased understanding of science as it is practiced, increased understanding and overall confidence in science topics, and enthusiasm and confidence for teaching science in future classrooms. Last but not least, the authors reviewed surveys on how students felt about the peer-review process and found that overall, students appreciated the opportunity to gain feedback and were not put off by constructive comments and suggestions. The majority of students demonstrated a strong increase in their overall understanding of the science topics covered in the course and as a result were also more confident about their abilities to teach them in the future.

In an effort to learn more about the emotional motivators behind teachers' use of school gardens, Simon Jorgenson outlines a study he conducted by interviewing three primary school teachers who utilized school gardens in their instructional practices (Jorgenson, 2014). Most of the data was gathered through utilization of established phenomenological methods, where the author extensively interviewed the three teachers individually at two separate times. All three of the teachers were involved in a wellestablished and well-supported school garden program, where the garden coordinators helped to tie specific state science standards into the garden curriculum. Furthermore, all 
three teachers had fond, nostalgic memories of being in the outdoors during their childhoods that made them more comfortable working in the garden. Analysis of the data showed that the teachers drew primarily from three internal sources: environmental memories, observations of children's behavior, and beliefs about teaching and learning. All of these factors are interpreted by the author to be internal sources of empowerment that are bolstered by external incentives, like linking garden lessons to state standards. Most importantly, the author found that the garden lessons had to be in line with allowing the teachers to practice their core beliefs about teaching and learning in order for teachers to continue to utilize school gardens as a medium of class instruction. At the time of the interviews, all three teachers believed that the gardens had proven to be a good opportunity for students to engage in outdoor activities that encouraged their creativity and imaginations. The next biggest factors in the utilization of gardens by the teachers involved access to resources including: additional training in horticulture, exposure to successful school garden programs, practices fit for local conditions, curriculum, lesson plans and activities that are linked to standards of learning, instruction on how to link all of this together, and ongoing support from volunteers.

Teaching efficacy is the main characteristic that demonstrates a consistent relationship with student achievement, and several researchers set out to investigate elementary school teachers' attitudes and feelings towards teaching science and what those feelings are based upon the findings of Ramey-Gassert, Shroyer, and Shaver (Ramey-Gassert et al., 1996). The authors surveyed twenty-three elementary school teachers who were involved in a project to enhance science, technology, and math 
education. Teachers were asked to self-report using the Science Teaching Efficacy Beliefs Instrument, In-service version (STEBI-A) and were scored on two subscalespersonal science teaching efficacy (PSTE) and science teaching outcome expectancy (STOE). Based on their scores in these two realms, ten teachers from the original group were selected to participate in interviews in order for the researchers to gain more insight into the teachers' overall attitudes and experiences. Throughout the interviews, the authors focused on learning more about internal and external motivations for teachers. One of the main themes that emerged from the interviews was that a teacher's current attitudes towards science are heavily based on previous experiences in science, both in school (formally) and out of school (informally). Recurring internal factors included desire for change or improvement, desire for collegiality, and image of self or role definition- which all correlate more strongly with the PSTE data. Four of the teachers in the study stated that after they attended science workshops and became acquainted with enthusiastic, knowledgeable science teachers, they themselves became more enthusiastic about teaching science. Most of the teachers noted that external factors like resources play a major role in their abilities to teach science effectively- correlating most strongly with the STOE data. Six of the teachers in the study stated that attending workshops and gathering better science teaching materials, as well as having the support of colleagues, built their confidence in teaching science. The main take away that Ramey-Gassert, et al. emphasize is that a consistent way to encourage support and foster change in teacher attitudes toward science is to create positive science learning environments for teachers through professional development. 
Self-efficacy is deeply rooted in lifelong experiences and internal factors. If a teacher wants to improve her confidence, in any area of teaching/learning not just science, there are powerful ways that she can address this. Ramey-Gassert, et al. (1996) found that one of the main themes that emerged from the interviews they conducted with teachers was their current attitudes towards science are heavily based on previous experiences in science, both in school and out of school. However, the researchers emphasize that an effective way to encourage, support, and foster change in teacher attitudes toward science is by creating (or recreating) positive science learning environments for teachers through professional development. In Simon Jorgenson's study (2014), he found that the most important factor in using a school garden for the teachers he interviewed was that it allowed them to practice their core beliefs about teaching and learning. As mentioned in the opening of this section of the literature review, Avery and Meyer (2012) found that way pre-service teachers learned science in the researchers' inquiry-based class has a significant effect on whether or not the students reported a more positive attitude toward science and an increased understanding of the nature of science. These examples outline the major undercurrent of how a teacher's science knowledge and confidence in that knowledge can greatly affect her attitude towards teaching science. In general, the firmer a teacher's self-efficacy foundation is, the greater the potential for positive impacts on her students becomes.

\section{Common Measurement}

Increasing student achievement, evaluating teacher pedagogical content knowledge (PCK), and learning more about self-efficacy are important factors in any 
conversation about education reform. But how do we measure those changes and know if the treatments or evaluations have been effective? A research endeavor that combined the topics mentioned above and provided support and examples of how to measure student achievement, PCK, and self-efficacy is The Common Measurement System (Saxton et al., 2013). It centers on conceptualization of a STEM common measurement system. There are three key areas of input that are integrated in a theory of change and that provide a foundation for future development of stronger assessments and evaluations of: professional development, teacher practices, and student performance. In order to gauge processes and successful outcomes in all these areas, the authors conducted an extensive literature review and selected validated instruments that would most effectively track progress. Items were identified in each area with regard to current shortfalls, suggested improvements and implementations, and recommended methods for collecting data/validating practices going forward. In summation, targeted professional development opportunities must be created in order to help teachers strengthen along pedagogical content knowledge and increase their own self-efficacy. Teachers must then engender supportive teacher-student relationships that foster an effective learning environment where the teacher's effective pedagogical content knowledge encourages higher-order conceptual problem solving and application in students. Students will be expected to engage in classroom activities, and given these resources and structure should be able to demonstrate higher-order cognitive skills around STEM topics as a result, making them better prepared to enter college or a career track comparatively. The authors outline the conceptualization of the practices and expectations in order to 
establish a foundation for implementation, data collection, and validation of what works and what doesn't work with regard to creating effective STEM curriculum in K-12 education from a professional development, teacher practice, and student performance standpoint.

\section{Summary}

School gardens have been shown to have positive impacts on student learning, comprehension, and problem solving in a variety of subjects and social aspects. In addition, teachers often value gardens as good resources for teaching a variety of subjects. Furthermore, teachers who have utilized school gardens often share that gardens provide many benefits for teachers as well, including the ability to teach interdisciplinary subjects, provide hands-on experiences, and cushion lesson plans in light of curriculum changes (Klemmer, Waliczek, \& Zajicek, 2005). Even if a teacher has never utilized a garden (or is uncomfortable doing so) several examples support the idea that professional development opportunities have helped teachers gain additional instructional practices and knowledge. As discussed in the third section of the review, a teacher's have strong instructional practices and self-efficacy can have a profound positive impact on students. However, a teacher's own attitudes toward science must be taken into account in order to see (and be able to change) the whole picture. Factors such as external resources and support, lesson development, and self-efficacy may play a considerable role in a teacher's ability to use a school garden as an effective learning environment. These themes provide a foundation for an investigation into how multiple factors can influence a teacher's decision to utilize a school garden. Rather than 
examining the influence of singular factors on garden use in instruction I incorporated methods that would provide data on several factors, including resources and teacher selfefficacy. 


\section{Methodology}

\section{Overview}

The goal of this research was to learn more about the factors that influence teachers' utilization of a school garden for the purpose of STEM learning in an elementary school environment. Therefore, the focus of my research revolved around the question: "What factors are most important to a teacher to feel effective in her use of a school garden to relay STEM concepts and practices?" My hypothesis was that these factors would be based mostly on a teacher's individual knowledge. I proposed a mixed methods, multiple case study design that will employ qualitative and quantitative data to examine the underlying factors in teachers' decisions to use their school gardens. The factors I examined in this case study were the internal factors of teacher's perceived strengths or weaknesses with regard to instructional practices and self-efficacy, as well as external factors including space, tools and seeds, principal/teaching group support, etc. The extent to which these variously affect individual teachers' garden use was the goal of this research project.

\section{Participants}

Eight first and second grade teachers from elementary schools within the Lakeridge school district participated in this case study. Historically, the districts Science and Technology Center (STC) has focused on second grade as the year that students are most involved in the school garden, so second grade teachers assumedly have the most familiarity with the school gardens. Several first grade classrooms within the district also utilize their school garden, however. Each school has anywhere between two and four 
second grade classrooms, and several schools have an additional 2nd/3rd grade split classroom. Classrooms have anywhere between eighteen and twenty five students. Their teachers have a variety of years of experience and expertise. There was good representation of differing levels of teacher tenure both within the school district and at each school. Table 1 includes key demographics of each primary school within the district.

Table 1- School demographic data from 2013-2014 school year, accessed via district website

\begin{tabular}{|c|c|c|c|c|c|}
\hline School & $\begin{array}{l}\text { Number } \\
\text { of } \\
\text { Students } \\
(\text { K-5) }\end{array}$ & $\begin{array}{l}\text { English } \\
\text { Language } \\
\text { Learners } \\
\text { (ELL) } \\
\end{array}$ & $\begin{array}{c}\text { Economically } \\
\text { Disadvantaged }\end{array}$ & $\begin{array}{l}\text { Test Scores } \\
\text { (compared } \\
\text { within the } \\
\text { state) } \\
\end{array}$ & Garden Description \\
\hline 1 & 523 & 9 & 34 & Average & Small, low use \\
\hline 2 & 539 & 19 & 44 & $\begin{array}{l}\text { Above } \\
\text { average }\end{array}$ & $\begin{array}{l}\text { Large, sits on STC grounds } \\
(0.5 \text { acre })\end{array}$ \\
\hline 3 & 479 & 16 & 39 & $\begin{array}{l}\text { Above } \\
\text { average }\end{array}$ & Medium size, low use \\
\hline 4 & 303 & $<5$ & 27 & $\begin{array}{l}\text { Above } \\
\text { average }\end{array}$ & $\begin{array}{l}\text { Large, utilized by multiple } \\
\text { grades and the community }\end{array}$ \\
\hline 5 & 496 & $<5$ & 8 & Average & $\begin{array}{l}\text { Medium size, high use, } \\
\text { volunteer garden coordinator }\end{array}$ \\
\hline 6 & 301 & no data & 14 & $\begin{array}{l}\text { Above } \\
\text { average }\end{array}$ & $\begin{array}{l}\text { Medium size, high use, } \\
\text { integrated into multiple grade } \\
\text { curriculums }\end{array}$ \\
\hline 7 & 510 & no data & 13 & $\begin{array}{l}\text { Above } \\
\text { average }\end{array}$ & Medium size, low use \\
\hline 8 & 324 & $<5$ & 17 & $\begin{array}{l}\text { Above } \\
\text { average }\end{array}$ & $\begin{array}{l}\text { Medium size, high use, } \\
\text { integrated into multiple grade } \\
\text { curriculums, volunteer garden } \\
\text { coordinator }\end{array}$ \\
\hline 9 & 558 & 5 & 20 & Average & Medium size, medium use \\
\hline
\end{tabular}

Within the Lakeridge school district, all of the primary schools have established gardens; all of these gardens are supported financially at varying levels by the school administration and/or parent-teacher association (PTA). All of the school gardens contain raised beds and are primarily used for small, seasonal vegetable crops. 
Additionally, the director of the STC has many years of general gardening knowledge as well as experience with gardening in a school garden specifically. He is able to support teachers directly if they have questions or concerns, however his ability to help by directly teaching second graders in the gardens changes from year to year. There is more support and resources available within this district than within similar districts in the Portland metro area.

Throughout the spring, I was able to help with garden lessons at seven of the nine primary schools, based on teachers' schedules and goals. Overall I worked with twenty four teachers, seven of them were first grade teachers and seventeen were second grade teachers. I worked with first grade classrooms at two of the seven schools based on individual school's desires for garden instruction for first instead of second grade. By the middle of March, I was able to recruit eight teachers from five of the schools I had helped at to volunteer to take part in this research. I was able to survey and interview two teachers from three of these five participating schools.

After getting more acquainted with the individual school gardens at which I worked, I discovered that two of the school gardens were actively utilized by second grade teachers at those schools (each coincidentally had an active volunteer garden coordinator). The remaining five school gardens were far less actively utilized by teachers, if at all. Figure 1 is a photograph of one of the schools' high use garden, while Figure 2 is a photograph of a low use garden. Both pictures were taken during the same time of year during the study. 
Figure 1- Photograph of a high-use garden in the Lakeridge school district

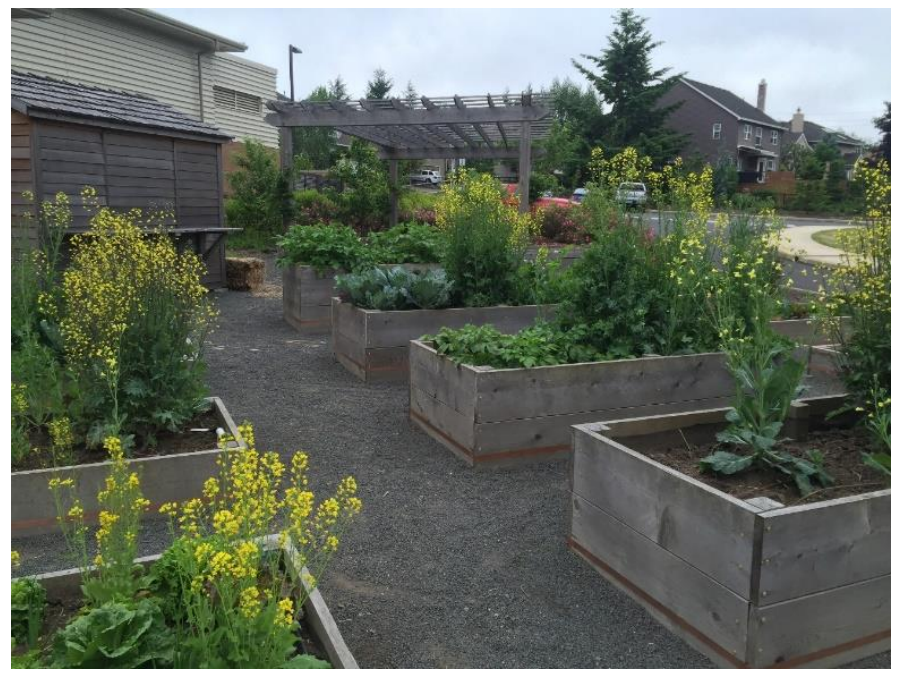

Figure 2- Photograph of a low-use garden in the Lakeridge school district

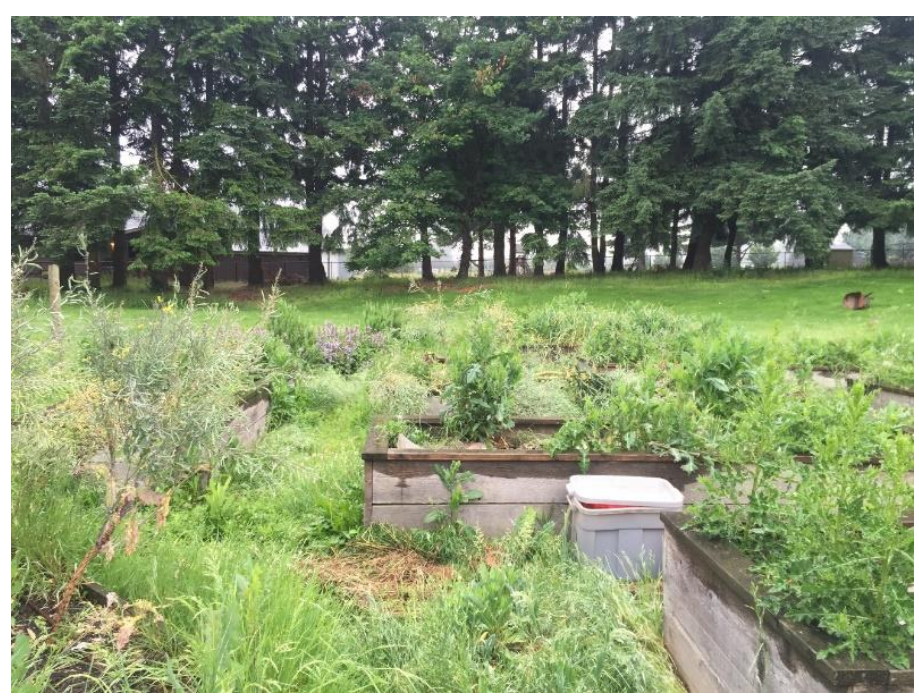




\section{Procedure}

In the spring of 2015, I worked with the STC to coordinate all aspects of class garden time with the second grade teachers, including scheduling, planning lessons, and gathering resources for planting. This involved approximately twenty-four classrooms and over five-hundred students. As a result of my participation in leading the garden lessons with the STC and casually talking with the teachers, I gained personal insight into what it's like to use a garden in instruction from a teacher, student, garden coordinator, research, and observer perspective. This informed my overall findings in a much richer way than my involvement from one perspective alone.

All teachers with whom I worked during the STC garden activities were made aware of the opportunity to participate in the study, and participation was entirely voluntary. There was no direct benefit to the participants of the study, however a possible indirect benefit is that the findings based on their participation may have an impact on the overall school garden program within the school district. Teachers did not directly mention this as part of their rationale for participating.

As part of my research project I administered two online surveys and conducted follow up interviews with the primary school teachers I had worked with as part of the garden lessons through the STC. The online surveys (Garden Resources and SelfEfficacy) each took about five minutes to complete, and teachers could access them online via SurveyMonkey (https://www.surveymonkey.com/) on their own time over about a three week period. Moving into the late spring, I continued to help organize logistics for classroom garden lessons, this time for the erosion unit, and also began 
setting up teacher interviews with the teachers who had taken the surveys. In order to gain additional validation of the Garden Resources survey itself as well as a deeper insight into their delineation process, I made it a point to ask about each teacher's reasoning behind their answers for the most important factor they indicated on their Garden Resources survey.

In the late spring of 2015, I reached out to teachers who had completed both of the surveys and requested their participation in an interview with me for the purpose of learning more about their responses and overall garden use. These interviews were conducted in a one-on-one, face-to-face environment. I codified responses and similar attributes that I learned about over the course of the interviews and explored how it correlated to the original surveys. Interviews served as a method to gain rich qualitative data about garden use and also as a way to reinforce the validity of the survey instruments. My expectation was that teachers would answer questions in the interview similarly to how they originally answered them in the surveys. However the interviews also provided additional insights that could not have been gleaned from survey data alone.

\section{Instruments}

Garden Resources. This instrument is an adapted survey from (DeMarco et al., 1999), wherein the researchers sent a survey out to hundreds of teachers who actively utilized school gardens within the state of California. It included eighteen items that were considered important factors or structures to the effective use of school gardens (see Figure 3). Teachers were asked to pick the five most important items and then rate those 
from 1-5 as most to least important. For example, items include things like: availability of site to grow plants, principal support, teacher's science knowledge, and access to shovels. Each teacher was also encouraged to write in any factors that she did not see in the list provided. After receiving the results of this initial survey, the researchers' list of items grew to thirty. I sent an adapted survey ( 24 items) to all second grade teachers within the school district that will be available for them online, and it should take approximately ten minutes to complete. The answers to these questions helped me to identify important factors and structures with regard to school garden use within the Lakeridge/ e school district specifically.

Figure 3- Garden resources survey [adapted from Demarco, et al. (1999)]

Pick the five most important factors you consider in utilizing the garden in your classroom. Rate the five chosen items from 1-5 (most important to least important):

1. Person with responsibility for school gardening activities

2. Availability of a site to grow plants

3. Availability of funding for supplies

4. Support of principal

5. Availability of gardening equipment

6. Adequate amount of instructional time

7. Teacher's gardening knowledge

8. Availability of volunteer help

9. Management of student behavior

10. Availability of a summer garden maintenance program

11. Adequate amount of preparation time

12. Availability of outside, expert help

13. Availability of support materials

14. Small class size

15. Availability of storage for supplies

16. Addressing safety concerns

17. Availability of garden based curriculum

18. Teacher's science knowledge

19. Student ownership of a gardening project

20. Integrating gardening with other subject matter

21. Adequate amount of preparation time

22. Long-range plan for gardening program

23. Management of student behavior

24. Teacher's science knowledge

25. Teacher's garden knowledge

26. Pressure to meet other academic requirements

27. Vandalism 
Self-efficacy. I surveyed teachers on their self-efficacy to learn the baseline idea of each teachers' feelings and attitudes towards teaching STEM topics in their classrooms, in case that is a major factor in their garden use. I used an adapted version of the Teacher Self-Efficacy survey adapted by the Portland Metro STEM Partnership, originally based on the Ohio State Teacher Efficacy Scale (Tschannen - Moran \& Hoy, 2002). The researchers examined self-efficacy instruments that have been utilized over the past forty years and based on those created a new survey (see Figure 4) that was shorter and more targeted/specific for the purpose of answering self-efficacy questions. I asked the teachers to reflect and rate themselves on a scale of 1-9 ("none at all" to "a great deal") when it comes to items like, "How much can you do to get through to the most challenging students in science?" The survey was adapted to focus on efficacy for student engagement and efficacy for instructional practice and will include two questions around instruction based in a school garden. The online survey comprised of twenty-four prompts and take about ten minutes to complete. 
Figure 4- Self-efficacy survey [adapted from Tschannen-Moran \& Hoy (2002)]

Portland Metro STEM Partnership Teacher Self-Efficacy Survey

Common question stems are provided below. Teachers should be asked about disciplines separately and based on what is appropriate to the program, teaching assignment, or school.

Survey Scale:

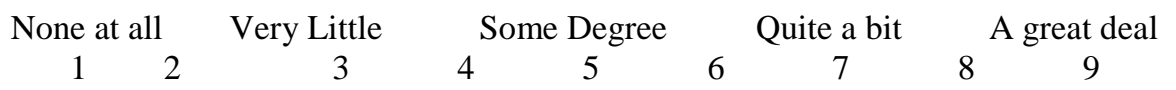

1. How much can you do to get through to the most challenging students in STEM disciplines?

2. How much can you do to help your students think critically about STEM disciplines?

3. How much can you do to control disruptive behavior in the classroom, in general?*

4. How much can you do to motivate students who show low interest in STEM school work?

5. To what extent can you make your expectations clear about student behavior, in general?**

6. How much can you do to get students to believe they can do well in STEM school work?

7. How well can you respond to difficult questions from your students in STEM disciplines?

8. How well can you establish routines to keep activities running smoothly, in general?*

9. How much can you do to help your students value learning in STEM disciplines?

10. How much can you gauge student comprehension of what you have taught in STEM disciplines?

11. To what extent can you craft good questions for your students in STEM disciplines?

12. How much can you do to foster student creativity in STEM disciplines?

13. How much can you do to get children to follow classroom rules, in general?*

14. How much can you do to improve the understanding of a student who is under-performing in STEM disciplines?

15. How much can you do to calm a student who is disruptive, in general?*

16. How well can you establish a classroom management system with each group of students, in general?*

17. How much can you do to adjust your lessons to the proper level for individual students in STEM disciplines?

18. How much can you use a variety of assessment strategies in STEM disciplines?

19. How well can you refocus students who are off-task to preserve the goals of your lesson, in general?*

20. To what extent can you provide an alternative explanation or example when students are confused in STEM disciplines?

21. How well can you respond to defiant students, in general?*

22. How much can you assist families in helping their children do well in STEM discipline school work?

23. How well can you implement alternative strategies in your classroom during STEM discipline lessons?

24. How well can you provide appropriate challenges for very capable students in STEM disciplines?

Scoring sub-scales of the survey (not visible to teachers)

Sub-scale

Items

Efficacy for student engagement

$1,2,4,6,9,12,14,22$

Efficacy for instructional practice

$7,10,11,17,18,20,23,24$

Efficacy for classroom mgmt. (general)

$3,5,8,13,15,16,19,21$

Teacher Interview. Finally, I asked teachers who completed both of these surveys to talk

with me during an interview about their responses to some of the items within both

surveys. The main purpose of the interviews was to gain richer qualitative data in order to

uncover a deeper understanding of how resources, self-efficacy, and instructional 
practices play into a teacher's decision to use a garden in her STEM instruction. The

format of this interview was semi-structured so that I could ask follow-up questions to learn more about ideas that the teachers raise in response to the initial questions (see

Figure 5).

Figure 5- Interview Questions

1. Tell me about your teaching background.

2. How comfortable do you feel about teaching science?

3. Have you used the garden to teach science topics before this year? (If yes) please tell me about it. (If no why not?)

4. What factors determine whether or not you use your garden for teaching?

5. Why did you rate (whatever the teachers rated \#1) as the most important factor necessary for using the school garden with your students? What about the least important factor?

6. Please rate each of the following with 1-5 points as something that would help you better use the school garden in your teaching:

a. Hands on, one-on-one help from a coordinator at THE STC

b. Easy access to online library of resources so that you could pick and choose

c. A specific garden curriculum that is linked to standards, like NGSS

d. The ability to call or email a THE STC coordinator for help

e. Other

7. How effective do you think that gardens could be for teaching STEM lessons? Why or why not?

8. If you were to plan a school garden unit that combined two or more subjects, which subjects might you choose? What might you have the students do?

Interviews ranged in time from twenty minutes to forty-five minutes and typically took place in the late afternoon after school got out. Conversations were conducted in a one-on-one, face-to-face setting. I focused on asking the teachers the open ended questions designed for the interview and only asking for more explanation if they gave a particularly short answer. The focus of this time was to learn more detail about teacher responses and gain a deeper understanding of what they perceive to be barriers and supports to utilizing their school gardens in their curriculum. I also asked specific 
questions about the different resources they use to teach science in their classrooms and also how effective they think a school garden can be in teaching about certain science topics (see Figure 5). This deeper understanding lent insight into data from the surveys and the interview is a valuable opportunity to gain insight that could not be gleaned from surveys where respondents can only rate pre-determined answers. 


\section{Results}

In the early spring, I worked primarily with second grade teachers and several first grade teachers to organize garden learning time for their classrooms. I researched and designed an erosion lesson I was going to teach in the late spring, which tied in to district standards for second graders. Based on my personal observations during the time I spent instructing in the garden, I found that most of the students were really excited to get out into the garden and that they usually behaved fairly well given the non-classroom structure. I made an emphasized effort to give them a lot of opportunities to come up with their own answers, to ask about their observations, and to let them come up with their own solutions. The students seemed to get especially excited about who could get their hands the dirtiest. There was always an opportunity for students to try a vegetable straight out of the garden, and they would often try the fruit or vegetable and remark on how good it was.

The eight teachers who participated in the study leant a great deal of value and insight into how the school gardens are utilized within the Lakeridge school district. Table 2 includes a brief description of each teacher's years of experience, garden use, and self-efficacy survey scores (names replaced with pseudonyms). 
Table 2- Teacher descriptions

\begin{tabular}{|c|c|c|c|c|c|c|c|}
\hline \multicolumn{5}{|c|}{ Participating Teacher Descriptions } & \multicolumn{3}{|c|}{$\begin{array}{c}\text { Self-Efficacy Scores } \\
\text { (self-rated) }\end{array}$} \\
\hline Teacher & School & $\begin{array}{c}\text { Years } \\
\text { Teach- } \\
\text { ing }\end{array}$ & $\begin{array}{l}\text { Grade } \\
\text { Level }\end{array}$ & Use of Garden & $\begin{array}{c}\text { Area } \\
1\end{array}$ & $\begin{array}{c}\text { Area } \\
2\end{array}$ & $\begin{array}{c}\text { Area } \\
\mathbf{3}\end{array}$ \\
\hline Katie & 1 & 2 & 1 & $\begin{array}{l}\text { Frequent, comfortable taking class } \\
\text { out for garden explorations and } \\
\text { comfortable teaching in the garden, } \\
\text { high confidence in designing } \\
\text { lessons }\end{array}$ & 9.0 & 9.0 & 9.0 \\
\hline Nancy & 1 & 12 & 2 & $\begin{array}{l}\text { Often, mid-range confidence in } \\
\text { taking students out into garden, } \\
\text { low confidence in designing } \\
\text { lessons }\end{array}$ & 7.8 & 7.9 & 7.9 \\
\hline Claire & 2 & 7 & 2 & $\begin{array}{l}\text { Frequent, comfortable taking class } \\
\text { out for garden explorations and } \\
\text { comfortable teaching in the garden, } \\
\text { mid }\end{array}$ & 6.8 & 7.1 & 7.1 \\
\hline Lindsey & 2 & 19 & 2 & $\begin{array}{l}\text { Often, mid-range confidence in } \\
\text { taking students out into garden, } \\
\text { mid-range confidence in designing } \\
\text { lessons }\end{array}$ & 7.8 & 8.6 & 8.2 \\
\hline Susan & 3 & 19 & 2 & $\begin{array}{l}\text { Frequent, comfortable taking class } \\
\text { out for garden explorations and } \\
\text { comfortable teaching in the garden, } \\
\text { high confidence in designing } \\
\text { lessons }\end{array}$ & 7.3 & 7.3 & 7.2 \\
\hline Anabel & 4 & 5 & 1 & $\begin{array}{l}\text { Often, mid-range confidence in } \\
\text { taking students out into garden, } \\
\text { low confidence in designing } \\
\text { lessons }\end{array}$ & 6.0 & 5.9 & 6.1 \\
\hline Angela & 5 & 9 & 2 & $\begin{array}{l}\text { Often, mid-range confidence in } \\
\text { taking students out into garden, } \\
\text { low confidence in designing } \\
\text { lessons }\end{array}$ & 6.9 & 7.1 & 7.0 \\
\hline Emily & 5 & 10 & 2 & $\begin{array}{l}\text { Often, mid-range confidence in } \\
\text { taking students out into garden, } \\
\text { mid-range confidence in designing } \\
\text { lessons }\end{array}$ & 6.5 & 8.3 & 7.6 \\
\hline
\end{tabular}

Self-Efficacy Labels Key:

Area 1 Student Engagement

Area 2 Instructional Practice

Area 3 Classroom Management (general) 


\section{Garden Resources Survey}

The Garden Resources survey was analyzed by combining the results of all the surveys from the teachers to see how each item rates at an overall level for the teachers who participated in this study. In Figure 6, factors were tallied for overall number of times they were included in a teacher's ranking of the five most important aspects of using her school garden, regardless of teacher ranking. Table 3, on the other hand, shows averaged rankings when factors were rated by at least two or more teachers. 
Figure 6- Number of times factor was included in overall rating

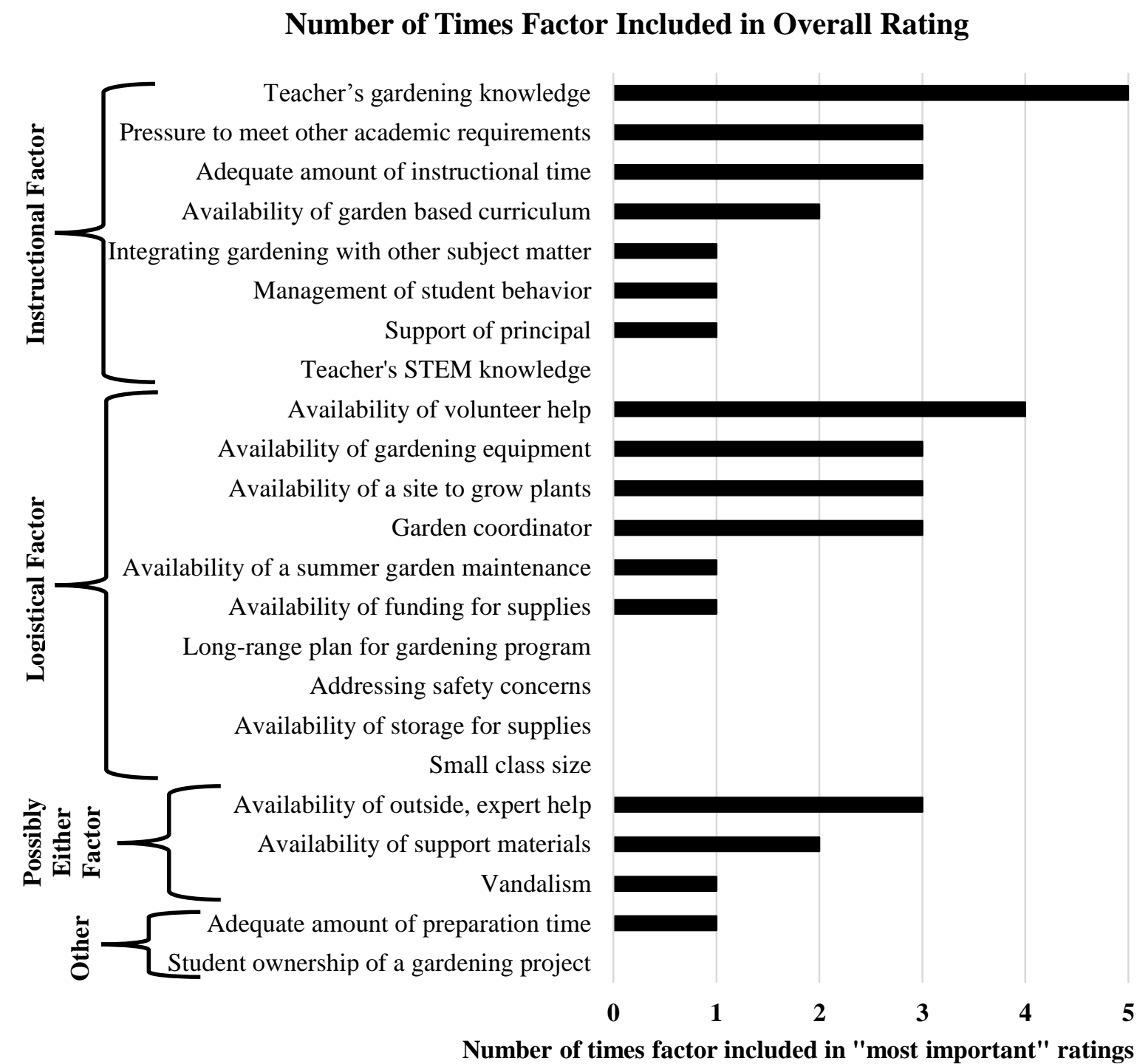

Figure 6- This chart outlines the number of times each survey choice was included, regardless of ranking/score, in the teachers' overall determinations of the most important considerations of their school gardens. Teachers were asked to choose the five most important factors from a set of survey choices and then rate those from 1-5 in order of descending overall importance. 
Table 3- Average ranking when rated by two or more teachers

\begin{tabular}{|c|c|c|c|c|c|c|c|c|c|}
\hline \multirow{2}{*}{\multicolumn{3}{|c|}{$\begin{array}{l}\text { Average Component Ranking when Ranked by Two or } \\
\text { More Teachers }\end{array}$}} & \multicolumn{7}{|c|}{ Rating } \\
\hline & & & \multicolumn{2}{|c|}{$\begin{array}{c}\text { More } \\
\text { Important }\end{array}$} & & & & \multicolumn{2}{|c|}{$\begin{array}{c}\text { Less } \\
\text { Important }\end{array}$} \\
\hline & $\begin{array}{l}\text { Overall } \\
\text { rating } \\
\text { (Fig. 6) }\end{array}$ & Component & $\begin{array}{l}\text { Logist. } \\
\text { or } \\
\text { Instruct. } \\
\text { Barrier }\end{array}$ & 1 & 2 & 3 & 4 & 5 & $\begin{array}{c}\text { Total } \\
\text { Ratings }\end{array}$ \\
\hline \multirow{8}{*}{$\begin{array}{c}\text { More } \\
\text { Important }\end{array}$} & 2.0 & Person with responsibility for gardening activities & Logist. & 1 & 1 & 1 & & & 3 \\
\hline & 2.0 & Pressure to meet other academic requirements & Instruct. & 1 & 1 & 1 & & & 3 \\
\hline & 2.5 & Availability of support materials & Logist. & 1 & & & 1 & & 2 \\
\hline & 2.7 & Availability of outside, expert help & Instruct. & & 2 & & 1 & & 3 \\
\hline & 3.4 & Teacher's gardening knowledge & Instruct. & & 2 & & 1 & 2 & 5 \\
\hline & 3.5 & Availability of volunteer help & Logist. & & & 2 & 1 & 1 & 4 \\
\hline & 3.7 & Adequate amount of instructional time & Instruct. & & 1 & 1 & & & 2 \\
\hline & 4.0 & Availability of a site to grow plants & Logist. & 1 & & & & 1 & 2 \\
\hline \multirow{2}{*}{$\begin{array}{c}\text { Less } \\
\text { Important }\end{array}$} & 4.0 & Availability of garden based curriculum & Instruct. & & & & 2 & & 2 \\
\hline & 4.7 & Availability of gardening equipment & Logist. & & & & 1 & 2 & 3 \\
\hline
\end{tabular}

\section{Self-Efficacy Survey}

The self-efficacy surveys was scored by adding up the self-reported values assigned by individual teachers for each prompt, with a higher score correlating directly to higher self-efficacy. Teacher scores were sought primarily to establish a baseline of teachers' self-efficacy in STEM topics specifically to see if that was a major factor in any of their decisions to use their school gardens. All teachers scored mid- to highconfidence levels with regard to their responses. See Table 2 for specific scores.

\section{Interviews}

With regard to analyzing the interview portions, I asked all the teachers similar questions and after the interviews were completed I re-listened to the recorded interviews and identified common themes. I found that there are a variety of factors contributing to 
individual teachers' garden use, but that each factor is a facet of either "Instruction" or "Logistics" and are often a combination of both factors.

In an effort to incorporate the valuable qualitative data gleaned from the interviews, I have summarized interviews from three different teachers as case studies below. Their names have been exchanged with pseudonyms, but the views held by these three teachers represent many of the overall highlights and challenges of a school garden experienced by all eight interviewed teachers. Each teacher also had intriguing personal insights that I wanted to capture and emphasize as part of the findings.

\section{Case Study 1}

Katie has a background in art, but has always felt like she had a good understanding of science. She's been teaching at the primary level for two years and really enjoys using the garden because she thinks it helps her students conceptualize abstract topics, like life-cycles, metamorphosis, and weather patterns. She feels like science is a great way to get kids engaged in subjects like math, reading, and writing because it grabs their attention regardless of their feelings about other subjects or school in general. She feels like a lot of teachers are somewhat nervous about teaching science. Overall, she has high self-efficacy (see Teacher 8 in Figure 3) and a deep appreciation for science.

During the interview portion, Katie talked about how gardening and being in nature in general is good for kids in so many ways. It gets them outside, using their hands, and disconnecting from the often highly structured school environment. She thinks that gardens are a great way to teach students emotional intelligence, in part due to 
finding a connection with nature, but also because working in a garden often involves taking care of something living. This aspect also gives students a sense of responsibility and ownership. One of the strongest opinions that Katie has is that a school garden provides opportunities for all children from all economic backgrounds to take part in growing and taking care of something. Many of her students who live in poverty don't have regular access to much outdoor space, including gardens, so a school garden is an important and powerful way to supplement that.

In addition to STEM topics, Katie also thinks that the garden provides a great opportunity for increasing student vocabulary, on both the science side and in general (think "shovel" or "harvest"). For that reason, she also thinks it is really great as an avenue for non-fiction writing, which she said can be really challenging for young children. Katie's biggest barrier to using the garden is logistical support. Although her classroom management score was high, she finds it is really challenging to take classes out into the garden without help from at least one other person, be that a parent or a garden program coordinator. Coordination of what/when/where things will be planted is also a little tricky at her school site because of the size and location of their garden. She feels like she needs the support of a teacher team or parents to enable her to have more time to focus on her garden lesson pedagogy and less time on general garden maintenance or resource coordination. She mentioned that a teacher really needs to care about the garden and make it her "baby," otherwise it gets cast aside in light of more immediate requirements. 


\section{Case Study 2}

Emily has been a teacher at the primary school level for ten years. While she thinks science is very interesting and enjoys learning more about it, she doesn't consider herself particularly strong in that subject area. Her self-efficacy scores were on the higher end of teachers' overall self-ratings (see Teacher 4 in Figure 3), and she mentioned that she definitely feels more comfortable with teaching science now than she did at the beginning of her career. Overall, Emily feels like she is usually able to design and teach solid, high-quality STEM lessons to her students. She also feels like she is more confident about using the garden than a lot of the other second grade teachers.

Based on our conversation, it sounds like Emily does a lot of her own research to learn about what she wants to teach her kids. Because she has to teach herself before she teaches her students, she mentioned that it is also nice to have access to a lot of resources, which she said is unfortunately often a limiting factor. There is a very active parent group helping to coordinate garden planting, maintenance, and other logistics, which Emily mentioned was very helpful because it allows her to use the garden when it works for her class, but she doesn't have to maintain it year-round in order to do so.

For her, the biggest constraints to using her school garden are weather and time. She mentioned that spring is a busy time and it's hard to fit gardening in with everything else going on, including testing, field trips, other projects, etc. For this reason, she thinks it would be nice to have the garden located near the playground so that the kids could have more ownership and also use it more informally. Emily mentioned the students' ownership a lot which she thinks is a really important piece of their overall level of 
engagement and participation. Emily pointed out that she thinks students experience a lot of success in science and they really want to be involved in what's going on, which is not always the same attitude they have towards math or reading or writing.

\section{Case Study 3}

Anabel has been teaching for several years now, however it was not her original goal to have a career in formal education. Her experiences in environmental education inspired her to pursue a more traditional teaching path. She had the lowest average STEM self-efficacy score (see Teacher 2 in Figure 3), but has a deep appreciation for nature and science, citing her positive experience growing up surrounded by nature. She thinks that kids really need hands-on, real-world experiences, and that they get so much more out of it when they are using multiple senses. Anabel thinks that getting kids away from screens and using all of their senses to build a connection to nature is positively influenced by a garden. She really tries to make sure that her students' experiences are memorable, unique, and positively associated.

Anabel uses her school's garden mostly for teaching about plants, but would like to combine engineering, technology, and gardening and incorporate that into her curriculum. During lessons based in the garden, she relies heavily on parent volunteers to help wrangle the twenty-five students she has on average. Wrangling her young students in the very large school garden is what she sees as her biggest struggle. Time, especially in the busy spring, is another factor for her.

Anabel talked about how it would be great to learn more about how to utilize the garden in the winter, when there are fewer scheduling constraints. The school that 
Anabel works at has a very active group of parents who help maintain the garden over the summer so that students and teachers have live plants to come back to in the fall. The principal is also quite supportive and takes on many of the scheduling and logistical facets of garden maintenance.

In general, Anabel feels like she can handle designing and teaching STEM lessons, but appreciates help in that process from other teachers or professional development opportunities. She is somewhat confident in her overall science knowledge and instructional practices, feels like she has a really good handle on plants and animals, an ok handle on light, but not a great handle on her earth/sun/moon unit. Anabel mentioned several times that the school does not have a prescribed curriculum which makes it hard to know what to do or where to start. While she feels fairly comfortable teaching her students about plant life-cycle changes, she mentioned that getting a hold of additional curriculum and resources would enhance her overall abilities and knowledge.

\section{Interviews Summary}

All of the teachers that I interviewed were strong proponents of the benefits of using a school garden and believed that these spaces could be powerful ways to help their students learn about different STEM topics, from pollination to erosion. Most of the teachers used their gardens as settings for teaching science lessons- primarily plant growth and pollination. However, all of the teachers I interviewed agreed that their school garden provides a variety of education opportunities including math, science, language arts, and environmental education (see Table 4). Many of them described their lessons as relying heavily on observations regardless of the learning topic. 
Table 4- Teacher Interview Responses

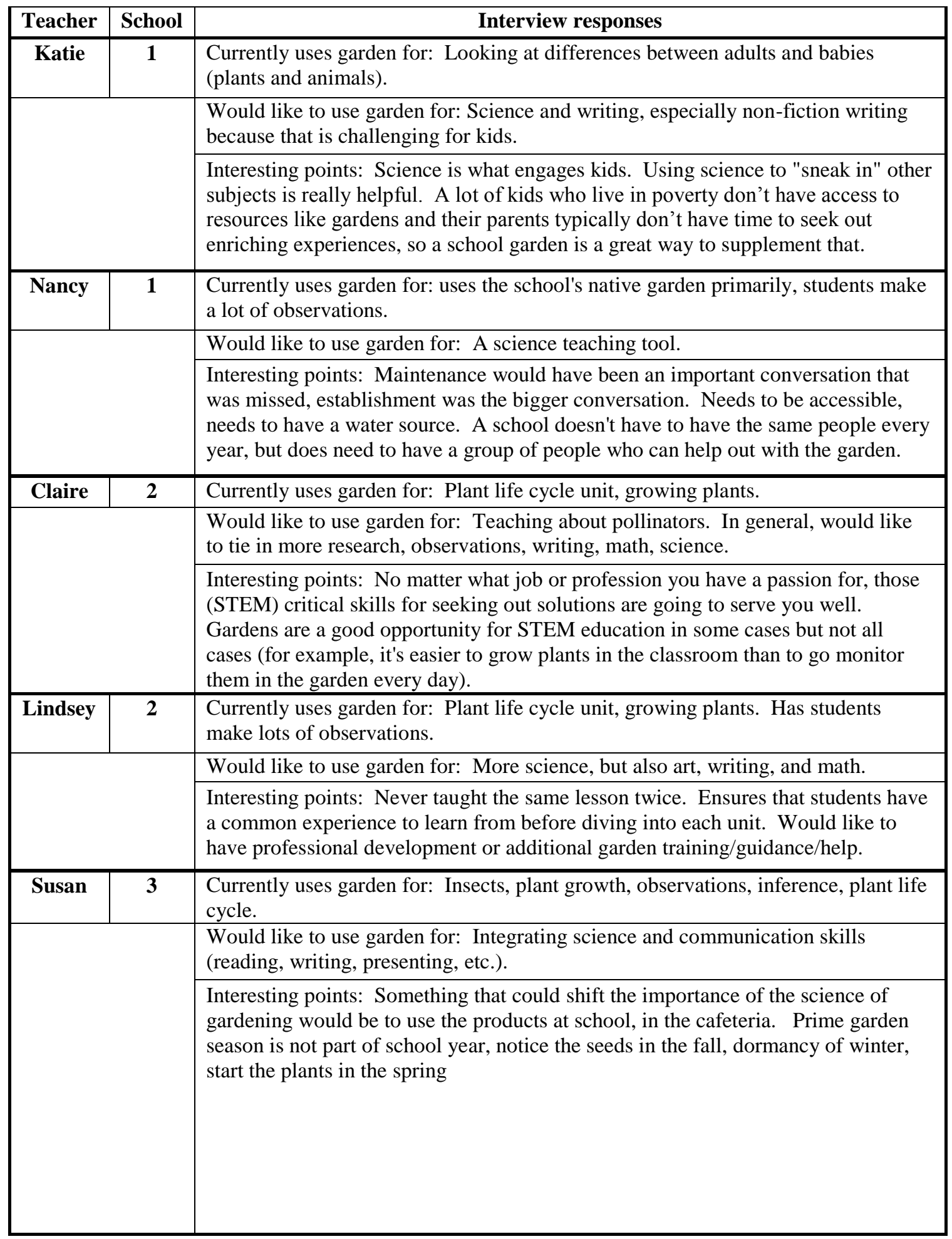


Table 4 continued:

\begin{tabular}{|c|c|c|}
\hline Teacher & School & Interview responses \\
\hline \multirow[t]{3}{*}{ Anabel } & \multirow[t]{3}{*}{4} & $\begin{array}{l}\text { Currently uses garden for: Teaching animal/plant unit in the garden. Class plants } \\
\text { tomatoes, peas, squash and lettuce. Notice how plants grow and how they look } \\
\text { different. }\end{array}$ \\
\hline & & $\begin{array}{l}\text { Would like to use garden for: Wants to teach earth/sun/moon unit with use of } \\
\text { garden, use the garden in the non-growing season, and teach technology and } \\
\text { engineering in the garden. Would like to tie garden into already developed lessons. }\end{array}$ \\
\hline & & $\begin{array}{l}\text { Interesting points: Garden gives teachers an opportunity to co-create units. Parent } \\
\text { volunteers are crucial to the summer success of the garden, because of them there } \\
\text { was this awesome sunflower bed ready for art projects in the fall. Would like to } \\
\text { have professional development or additional garden training/guidance/help. }\end{array}$ \\
\hline \multirow[t]{3}{*}{ Angela } & \multirow[t]{3}{*}{5} & Currently uses garden for: Plant growth and pollinator observations. \\
\hline & & $\begin{array}{l}\text { Would like to use garden for: Would do reading and math (predictions, space) or } \\
\text { engineering; Reading is a natural component of research, would be nice to tie more } \\
\text { of that in. }\end{array}$ \\
\hline & & $\begin{array}{l}\text { Interesting points: Principal has been helpful in coordinating grades' } \\
\text { responsibilities, which has been really helpful logistically. Would like to have } \\
\text { professional development or additional garden training/guidance/help. }\end{array}$ \\
\hline \multirow[t]{3}{*}{ Emily } & \multirow[t]{3}{*}{5} & Currently uses garden for: Plant growth and pollinator observations. \\
\hline & & Would like to use garden for: More math in the garden. \\
\hline & & $\begin{array}{l}\text { Interesting points: Science can often give students a lot of success (especially } \\
\text { students who don't experience success in every other subject) }\end{array}$ \\
\hline
\end{tabular}

Furthermore, every one of the teachers talked about the advantages of hands-on learning for students in their interviews (A Framework for K-12 Science Education, 2013), especially for abstract concepts (Flick, 1993). Multiple teachers also made the connection between positive outcomes for their students' learning related to the direct, hands-on experiences in the garden that made classroom activities relevant (D. Williams \& Dixon, 2013). As shown in Table 5, three of the teachers in this study appreciate how gardens naturally prompt students' inquiry and learning about complex topics. Several teachers in my study also discussed similar themes of the advantages of student colearning through hands on engagement and problem solving (Kelley \& Williams, 2013). Many of the teachers also discussed how their school gardens promote emotional 
intelligence (Blair, 2009) and a sense of responsibility for their students that is often hard to replicate in the classroom.

Table 5- Perceived student benefits of using the school garden

\begin{tabular}{|c|c|c|c|c|c|c|c|c|c|}
\hline \multicolumn{10}{|c|}{ Perceived Benefits of School Garden Use } \\
\hline Teacher & Katie & Nancy & Claire & Lindsey & Susan & Anabel & Angela & Emily & \\
\hline School & 1 & 1 & 2 & 2 & 3 & 4 & 5 & 5 & Mentions \\
\hline $\begin{array}{l}\text { Naturally } \\
\text { promotes inquiry }\end{array}$ & $\checkmark$ & & $\checkmark$ & & & & $\checkmark$ & $\checkmark$ & 3 \\
\hline $\begin{array}{l}\text { Makes science } \\
\text { real/ Conceptual- } \\
\text { ization of } \\
\text { abstract topics }\end{array}$ & $\checkmark$ & & $\checkmark$ & $\checkmark$ & & & $\checkmark$ & & 4 \\
\hline $\begin{array}{l}\text { Hands on } \\
\text { activities }\end{array}$ & $\checkmark$ & $\checkmark$ & $\checkmark$ & $\checkmark$ & $\checkmark$ & $\checkmark$ & $\checkmark$ & $\checkmark$ & 8 \\
\hline $\begin{array}{l}\text { Creates a } \\
\text { connection to } \\
\text { nature }\end{array}$ & & $\checkmark$ & & $\checkmark$ & $\checkmark$ & & & & 3 \\
\hline $\begin{array}{l}\text { Employs } \\
\text { multiple senses }\end{array}$ & $\checkmark$ & & & $\checkmark$ & & $\checkmark$ & & & 3 \\
\hline $\begin{array}{l}\text { Serves } \\
\text { underserved } \\
\text { populations }\end{array}$ & $\checkmark$ & & & & & & & & 1 \\
\hline $\begin{array}{l}\text { Break from } \\
\text { screen time }\end{array}$ & & & & $\checkmark$ & $\checkmark$ & $\checkmark$ & & & 3 \\
\hline $\begin{array}{l}\text { Teaches } \\
\text { emotional } \\
\text { intelligence and } \\
\text { responsibility }\end{array}$ & $\checkmark$ & & & $\checkmark$ & & & & $\checkmark$ & 3 \\
\hline $\begin{array}{l}\text { Creates a link to } \\
\text { other subjects }\end{array}$ & $\checkmark$ & & & & & & $\checkmark$ & $\checkmark$ & 3 \\
\hline
\end{tabular}

The main themes that emerged from conversations with teachers was that they struggled with 1) designing curriculum that both utilized the garden and aligned with standards, 2) coordinating volunteer help 3) coordinating an overall garden plan with other teachers 4) maintenance and 5) managing students (see Table 6). When separated into the two themes, teachers' perceived limitations when utilizing their school garden, 
points number 1 and 5 can be attributed to instructional constraints, whereas points 2,3 , and 4 can be attributed to logistical constraints. Point 5 can also be interpreted as a logistical constraint due to the fact that a teacher would have to coordinate parent or volunteer help in the garden in order to complete a lesson.

Table 6- Perceived barriers to teachers when utilizing their school garden

\begin{tabular}{|c|c|c|c|c|c|c|c|c|c|}
\hline \multicolumn{10}{|c|}{ Perceived Barriers to School Garden Use } \\
\hline Teacher & Katie & Nancy & Claire & Lindsey & Susan & Anabel & Angela & Emily & \multirow{2}{*}{$\begin{array}{c}\text { Total } \\
\text { mentions: }\end{array}$} \\
\hline School & 1 & 1 & 2 & 2 & 3 & 4 & 5 & 5 & \\
\hline $\begin{array}{l}\text { Ability to create } \\
\text { garden-based } \\
\text { lessons }\end{array}$ & & $\square$ & $\checkmark$ & & & $\checkmark$ & $\checkmark$ & & 3 \\
\hline $\begin{array}{l}\text { Competition } \\
\text { against other } \\
\text { subjects or } \\
\text { academic } \\
\text { standards }\end{array}$ & & $\checkmark$ & & & $\checkmark$ & & & $\checkmark$ & 3 \\
\hline $\begin{array}{l}\text { Connecting } \\
\text { garden outside } \\
\text { of growing } \\
\text { season }\end{array}$ & & & & & $\checkmark$ & $\checkmark$ & & & 2 \\
\hline $\begin{array}{l}\text { Need for Garden } \\
\text { Manager }\end{array}$ & & $\checkmark$ & & & $\checkmark$ & & $\checkmark$ & & 3 \\
\hline $\begin{array}{l}\text { School day } \\
\text { schedule }\end{array}$ & & $\checkmark$ & & $\checkmark$ & & & & $\checkmark$ & 3 \\
\hline $\begin{array}{l}\text { Parent } \\
\text { volunteers to } \\
\text { help during } \\
\text { lessons/ } \\
\text { Wrangling } \\
\text { students }\end{array}$ & $\checkmark$ & & & & & $\checkmark$ & $\checkmark$ & & 3 \\
\hline Maintenance & $\checkmark$ & $\checkmark$ & & & $\checkmark$ & & & & 3 \\
\hline Weather & & $\checkmark$ & & $\checkmark$ & & & & $\checkmark$ & 3 \\
\hline
\end{tabular}

Points associated with Instruction could be split further into 1) use of the garden sandwiched between other activities within a school day (field trips, music, PE, etc.), and 2) time to research and develop lessons geared towards that garden that also align with standards. Teachers cited scheduling garden time against other activities as the biggest 
puzzle piece for them to solve, as there are so many different activities and schedules that need to be coordinated on a daily basis. That said, three teachers mentioned that help with building a lesson and aligning it to standards was a barrier for them, based on either their knowledge in STEM or garden topics, or their ability to align their garden knowledge with their STEM knowledge.

All of the teachers mentioned that logistical factors are a huge aspect of their school garden use. Logistics can also be broken into sub-categories: 1) organization of support during the actual garden lesson and 2) logistical coordination of maintenance and planning throughout the school year. Teachers often talked about the fact that wrangling upwards of twenty five students in an outdoor setting can be really tricky, and that the ability to break students into smaller groups that are each led by an adult is a key factor to success. For this reason, the support of parent volunteers, a garden coordinator, or another "helper" is often a deciding factor as to whether or not a teacher will take her students out into the garden.

A point that came up in both the survey and the interview was that teachers did not wish to carry the entire responsibility for the maintenance and use of their school garden, no matter how many square feet it encompasses. Caring for a garden takes time and some gardening knowledge. Teachers more often than not said that they couldn't make the time commitment, but a lack of gardening knowledge was also a consideration for at least three of the teachers. Even if a teacher doesn't have gardening knowledge, but wants to contribute to the growth of a school garden, the coordination of maintenance, plot designations for different classes, funding, etc. can become a 
considerable amount of work. One of the teachers whom I spoke with (who had many years of experience and garden expertise at other schools within the district) said that one of the things she thought was a big barrier for their school was that it was so new. This teacher said that because the teachers and administration are still in the process of bringing together all of the other factors that are involved in creating a great learning environment for students, garden care is not a top priority at this time (though she thinks it will be in the next two to three years).

Overall, teachers shared a great deal about how they utilized their school gardens and the value they saw in the spaces for student learning potential. Teachers also shared the barriers they saw to using their school gardens more frequently or to a fuller potential, which was perhaps more valuable than their comments about factors they saw as benefits. There is a wealth of published literature on the benefits of gardening from many perspectives and to the benefit of many audiences (Blair, 2009; Jorgenson, 2014; Kelley \& Williams, 2013; D. R. Williams, 2012). However, there is less information available about factors that teachers see as barriers to school gardens. In order to begin to take down those barriers, educators must first know what it is they're tackling.

\section{Research Limitations}

When I first began talking with the teachers about this project, I found that those who were either officially or unofficially in charge of their school garden were the ones who most readily volunteered to be participants. This may have introduced a participant bias into my study- those who support the use of the school garden are predictably going to be more likely to get involved in a research project centered on school gardens. 
Unpredictably, however, several teachers who were the garden leaders at their school were also teachers who had the least garden knowledge and/or lower self-efficacy for teaching in the garden or teaching STEM topics. Therefore, while there may have been a tendency for teachers involved in this project to be proponents of school gardens, their reasons for supporting all those soil plots at a more metacognitive level was that they saw the garden as a powerful, enriching medium for their students. 


\section{Discussion}

Based on the results from the Garden Resources survey and teacher responses during the interview it became apparent that teacher participants in this case study saw definite student benefits to utilizing their school gardens. However, there were also barriers that prevented teachers from using their school garden to a greater potential. These were primarily associated with limitations involving Instruction and Logistics. The availability of support in both of these areas is a major factor in whether or not teachers choose to utilize their school gardens. This case study adds deeper qualitative insight into the intricacies of how perceived benefits and barriers affect a teacher's use of their school garden. It also sheds more light on why teachers use school gardens despite individually perceived hurdles.

\section{Instructional Barriers}

One of the biggest perceived barriers to these teachers' utilization of their school garden was time for instruction with regard to pressure to meet other academic requirements, as seen in Table 6 and as supported by the literature (Graham \& ZidenbergCherr, 2005), (DeMarco, Relf, \& McDaniel, 1999). There is a lot of pressure and only so much time in a day, week and school year for a teacher to fit in all of the learning targets for her students, and it takes careful planning, time management and decisions based on overall benefits to the students. One teacher mentioned that she would love to work more in the garden, but the transition time alone from classroom to garden and back nearly took up the time she had allotted for science instruction each day. A solution for multiple teachers was to find a way to incorporate multiple subjects into their garden lesson. Not 
only does this make time constraints less of an issue, it can help the students make a stronger connection between the different subjects (Graham \& Zidenberg-Cherr, 2005).

Based on the teacher responses to the surveys and the interviews, the other biggest instructionally related barrier for teachers was with regard to designing and preparing for lessons. This finding is supported by several other papers, including: Demarco, et al (1999), from which the survey was adapted for this research project, as well as Graham \& Zidenberg-Cherr's (2005) paper, which outlines specific uses and barriers to garden use from teachers' perspectives. During their interviews, three of the teachers talked about their struggle to find appropriate curriculum to connect with the garden (see Table 6) whether that involved trying to find standards that they could feasibly integrate, or were simply trying to design a lesson they could do in the garden. One teacher mentioned her difficulty with adapting a lesson that connected something they had previously developed so that it could be taught with the garden (see Table 4, Anabel). Perhaps the issue that the teachers struggle with is trying to align the garden with their standards, where it may feel like they are trying to fit a round peg in a square hole. Instead, if they started with their standards and did some brainstorming and research for ideas on how to link that to the garden, lesson creation may be less challenging to "make fit." This is a similar approach to methods that were positively received in Kelley and Williams (2013) and Rey, Wei, and Barrett's (2010) teacher professional development programs.

There are many resources available should a teacher seek additional garden-based content knowledge. Over the course of my research and practicum, I discovered a great deal of high-quality (created by universities, non-profits, educators, professional 
gardeners or farmers, or some combination of these professions) lessons linking gardens with grade-level appropriate instructional outlines. These resources were often free and could be found online with a search string like: "second grade soil lesson," or "middle school garden biodiversity lesson.” School garden researchers have also found or introduced their own curriculum resources, one example being Junior Master Gardener lesson plans (Smith \& Motsenbocker, 2005). This practice would certainly require some amount of investigation and time on an individual teacher's part, but may not be as frustrating as trying to re-invent the wheel or force a lesson to fit.

Another option for helping teachers to gain resources and ideas for their own class garden use would be to bring them together and present them with the information in a workshop setting. Depending on how it is structured, this could give teachers an opportunity to discuss what they learn and even practice a lesson before taking it back to their own classrooms. Three teachers in this study mentioned that some form of professional development would be helpful (see Table 4) for their own development of garden-based curriculum, instructional practices, and overall gardening confidence. Even with piles of lesson ideas and clear goals for a lesson, creation and adaptation of curriculum can be time consuming- making garden-based activities less attractive for lesson development. Establishing opportunities for teacher training with assistance in linking lessons to standards may enhance levels overall of participation in the school garden, as evidenced by the findings from several papers including Ramey-Gassert, Shroyer, \& Staver (1996) and Graham \& Zidenberg-Cherr (2005). 
An example of how this type of opportunity could work within the Lakeridge school district would be for the STC to sponsor a garden workshop once or twice a year. Similar to Kelley and Williams' program in Portland (Kelley \& Williams, 2013), teachers in similar grades would have the opportunity to gain practical, subject matter, and pedagogical content knowledge together as well as share their own best practices. Another option would be for the district or the STC to design several grade-appropriate lesson outlines that align to standards set by the district and then distribute those to the teachers to use at their discretion and individually fit into their own schedules. Creating these types of reasonable opportunities (half-day workshops, several hours of support with garden-specific lesson planning, providing lesson outlines based on free resources from the internet, etc.) for teachers to adapt lesson outlines would also be something that would overcome the barrier of adapting curriculum to the garden.

The Lakeridge school district has fully adopted the Next Generation Science Standards (NGSS), and many of the core ideas and practices lend themselves well to garden-based lessons. For example, one of the performance expectations for second grade students is "Plan and conduct an investigation to determine if plants need sunlight and water to grow," (A Framework for K-12 Science Education, 2013) has a fairly straightforward connection to a school garden. Likewise, "Develop a simple model that mimics the function of an animal in dispersing seeds or pollinating plants" (A Framework for K-12 Science Education, 2013) would present an opportunity for students to get outside and move around the garden the way a pollinator or animal would. A teacher could develop a lesson where students learn about seed dispersal and pollination and then 
have the opportunity to apply their knowledge to demonstrating how this works by building a model or acting out the process. This type of hands-on learning has been shown to be effective for building higher order cognitive skills (Flick, 1993). An example like this also demonstrates an opportunity for students to apply their knowledge and skills to authentic problem solving, which is one of the main goals of the NGSS curriculum.

Powerful garden-based lessons combining strong research/planning practices with clear connections to the standards and strong classroom management methods can mitigate many of the challenges a teacher sees to using a garden instructionally. The more effective a teacher can be at making time spent in the garden worthwhile and meaningful, the greater the likelihood that both students and the teacher will draw positive correlations with the garden and what they all learn there. Instructional barriers are perhaps simpler to overcome at an individual level than some of the logistical barriers because so many of the barriers can be changed starting and ending with the individual teacher. She can choose to further investigate content, lesson plans, standards, and be inventive with how she implements that with her class.

\section{Logistical Barriers}

Logistical support was an equally important factor that teachers in this district considered when utilizing their school gardens, as evidenced by Figure 3 and Table 6. Logistical barriers are further separated in this discussion to address the differences between the logistics of garden maintenance as a whole and the logistics of using the 
garden as a setting for instruction during the school day from an individual teacher's perspective.

At the most basic level, the logistics of growing a school garden requires communication about who will plant what where and who will maintain what when. While a single teacher could feasibly handle that schedule, the more people who are involved, the more space there is, and the more physical and temporal resources it requires, the greater the amount of time it takes simply to manage that schedule. Similar to a point mentioned previously, a teacher's ability to schedule volunteers to help out with her class is also well within her individual realm of influence and control. However, if a school's goal is to have a successful school garden that is used by multiple grades and classrooms, the project will involve much more work and coordination on every front.

This increased workload quickly moves away from an individual teacher's abilities into a project that would be better served by a garden coordinator- be that a parent, volunteer, or school administrator. During teacher interviews, the point of having a garden coordinator (see Table 6) was mostly discussed as a solution to overall garden maintenance and logistical management- for example help with weeding, watering and knowing when/where/who is going to plant what was a high priority for teachers. Garden ownership (or a point-person) and spread of responsibility was something that teachers recognized as an important factor (see Table 3). Supporting this are the $91 \%$ percent of participants in the Demarco, et al (1999) survey, who responded that in order for a garden program to be successful, they felt there must be a leader who took responsibility for the overall state of the garden. 
The ability of parent volunteers, school administrators, or garden coordinators to support teachers by taking on the maintenance revealed itself as a considerable factor in whether or not a teacher will use her school garden. One of the teachers in this research study said that the most frustrating aspect her group missed when talking about establishing a school garden was a long-term plan for maintenance and integration. Everyone was so excited about getting a garden going that nobody thought about what that garden would involve one, two, even ten years in the future. Several solutions to this maintenance thorn include organizing parent/volunteer workdays, connecting with the local Master Gardeners, and creating an opportunity for the high schools or middle schools to organize a garden club could all contribute to the overall maintenance of the school gardens. Especially during the summer, families could adopt part of their school garden as their own or in lieu of renting a community plot. Tapping in to the resources and knowledge base of the community seems like a rich potential resource for knowledge and support for both the schools and teachers.

Three different teachers said in their interviews that they had no problem with regard to curricular instruction within the garden, but that they really struggled with keeping the attention of their twenty-odd second graders for any amount of time in a garden (see Table 6). The director of the STC discussed this, saying that students often associate being outside with being at recess, where they don't have to follow the norms of their classroom structure. This issue could certainly also be considered instructional or classroom management-based. However, the teachers' responses seemed to be more focused on the sheer number of students suddenly in an outdoor setting, not their ability 
to manage their students' behavior in general. One teacher said that she enlisted volunteers to lead a group in a fairly simple task (raking, breaking up dirt, watering, etc.), while she would teach the lesson to the other group. Once her activity was over, the groups would switch stations. She mentioned that, while this often took more work, students got a lot more out of their garden time in this scenario. This issue could also be addressed by enlisting a classroom volunteer or several for assistance with the gardenbased lesson.

Another consideration when trying to fit the garden into the school day was voiced by two different teachers who struggled with prioritizing what they consider enrichment activities (Table 6). There are many wonderful programs sponsored by the Lakeridge school district that are shared among the nine primary schools, three middle schools, and two high schools. These include a robotics program, farm-to-school project, fish hatchery field trips, and science fairs to name a few. Additionally, many of these teachers take their classes on field trips to the zoo, to the local museum of science and industry, to the art museum, and to parks and recreational spaces that have educational value. Stacked up against the logistical requirements of these activities and the space that they occupy in the schedule for the school year, these teachers struggled to fit gardenbased lessons in to a calendar already full of great activities that get their students out of the classroom and exploring the world around them. All things considered, and with no diminishment of the teachers' concerns, this is a relatively positive issue to have. Nonetheless, the competition of different enrichment activities doesn't have to carve such distinct delineations if time in a school garden is well planned and intentionally used. 
A suggestion that could alleviate both of these time-within-a-school-day barriers would be to really take a look at how to minimize transition time, or to turn it into something useful (e.g. Have the students make observations on their way to and from the garden, or model a "walking lesson" where the class talks about what they're learning as they walk). During my research practicum, I observed a teacher practice walking and talking during her trip to the garden and she kept most of her students engaged while preparing them for what they were about to do and see. Moreover, a garden-based lesson does not have to be long to be meaningful. Careful planning on the teacher's part can help to ensure that time spent in the garden is efficient yet impactful. Students can make weekly observations of how the biodiversity or plant cover in the garden is changing simply by walking through it. A teacher can split a lesson up over several days or assign different responsibilities/activities to different groups and a lesson can still have a positive impact students.

There are repeated examples above of suggestions that could help a teacher overcome the instructional or logistical barriers she sees to using a school garden in her instruction. Most of the suggestions are centered on teacher training and careful examination of how the garden will be used and how a garden-based lesson will accomplish student learning goals. While some of these suggestions may seem simple, they are in no way assumed to be easy to implement. If these solutions were obvious and easy to act on, then teachers would surely already have them figured out. What these teacher-perceived barriers instead uncover is that teachers feel limited instructional or logistical barriers to the resources that allow them to use their school gardens as true 
learning labs. Support for teachers from other teachers, school administration, volunteers, parents, and community members is necessary to help increase a teacher's familiarity with curriculum resources and her ability to use the garden as an extension of the classroom.

\section{Roadmap for Garden Success}

Culminating the practical knowledge I gained from surveying and interviewing primary school teachers with the theoretical and secondary knowledge based on school garden literature creates somewhat of a roadmap for how to get the most out of a school garden. Examples of successful school gardens (Edible Schoolyard, etc.) often revolve around the school garden being 1) closely linked to a support system or school culture where many people are involved in the maintenance of a garden and 2) integrated into more of the curriculum at a school-wide level. This greater level of integration often leads to greater long-term success. It becomes a bit of a circular argument that in order for a school garden to be useful instructionally it needs to be well-maintained, but in order for a garden to be well-maintained it needs to have a demonstrated place in a grade or school's curriculum to warrant the effort. Ensuring that a school garden is a worthwhile instructional setting and simultaneously a part of the school day that doesn't require a tremendous amount of logistical coordination is no small feat.

There seems to be a "sweet spot" where gardens are maintained regularly, utilized to their full potential, and not a burden to the teachers who want to use them. Gardens in these situations have overcome the threshold for usability as a learning lab vs. a regular, everyday garden. This is achieved via a clear plan for garden use, motivation and "buy- 
in" by at least several teachers to include it in their lesson plans. A great deal of success towards establishing a school garden comes from teachers being on board with the potential for a garden setting to be valuable instructionally, and then actively supported in developing their instruction (see Table 9). A key aspect of achieving this "buy-in" is ensuring that teachers see successful examples of gardens being used in curriculum or having measurable impacts on students, which was part of the findings in Ray, Wei, \& Barrett's (2010) paper.

It became clear during my conversations with teachers that the main burden of maintaining the garden needs to be removed from an individual teacher's plate. Delegation of parts and parcels of garden care and logistical scheduling would include a wider audience in the story of the garden, and could even engender a greater sense of responsibility and ownership among caretakers (D. R. Williams, 2012). One survey of published literature on school gardens outlines that that most well-established school garden programs attribute overall garden success and longevity to long-term and widespread support of the principal, teachers, parents, and students (Ozer, 2007). This supports the idea that a clear plan for the garden is perhaps one of the most important attributes of creating a successful school garden learning lab or program. This should outline: how, what, where and why using the garden fits into instruction naturally justifies this classroom setting both instructionally and logistically. Knowing who is going to plant what where and when (during the school year and in a school day) reduces confusion and research time among teachers and gives both teachers and their students more ownership over what and where they have planted. It is equally important to have a 
plan for the garden during all seasons. Coordinating community members to take care of the garden over the summer can take a lot of effort, but can also have a tremendous pay off when the garden is usable when school starts back up in the fall. Conversely, if a garden is not going to be used it can be put to rest so that opportunistic, fast-growing weeds don't take over during the time it isn't being actively maintained. Both of these plans add tremendous value to making and keeping a garden accessible.

A limiting factor to school garden use that wasn't mentioned in the interviews or surveys over the course of this research but has nonetheless sprouted in other studies, including Graham and Zidenberg-Cherr's (2005) research results, is the fact that gardens cost money to maintain. When one considers the cost of putting a garden in, the cost of taking one out, watering a garden, seeding a garden, and finding room in the budget to buy tools, the costs can add up quickly. This is another important aspect of support with regard to a school garden, and a consideration that teachers, teacher teams, schools, or districts should deliberate when deciding whether or not to establish a school garden. Current availability of time, support, and resources as well as a long-term plan that encompasses curriculum integration over multiple grade levels are key factors to the success of the establishment and propagation of a school garden.

There is one primary school within the Lakeridge district (that was not part of this study, unfortunately) where the principal has taken charge of her school's garden program for the past five years, setting up a clear plan and goals for the garden that are evaluated at least every quarter. She has also tasked her science teaching specialists with supporting teachers in developing their garden curriculum. Furthermore, the garden is 
part of the curriculum in every grade and is an area that students can easily visit during recess, giving the students in all grades more ownership and pride in their school garden. The result is that this garden is well-maintained and part of the learning community as a whole, which has become a naturally regenerative cycle for garden use and garden learning.

\section{Opportunities for Future Research}

A case study that incorporated the survey and interview aspects of this study but which also followed several teachers and assessed their garden lessons would lend insight into teachers' actual practices in a garden setting. This would create an opportunity to see how well-aligned teachers' survey and interview responses were with their "garden pedagogy", as well as uncover potential disconnects between teaching goals and what students actually gain while in the garden. During my literature search for this project, I did not come across any studies that delved into this.

Additionally, it would be interesting to study the processes of how teachers who are not specialists in a STEM field access and develop their STEM curriculum. Several of the teachers whom I talked with spent (what they felt was) an inordinate amount of time researching resources for their science and engineering lessons because they didn't know where to look or what they were looking for. The results from this kind of research would lend insight into how to best frame curriculum development support to make it more beneficial and useful for teachers.

Another avenue for future research is to assess how teachers would approach teaching engineering concepts by way of a school garden. There are a great deal of 
opportunities for practical problem solving within a garden, however it is not a connection that many of the teachers whom I spoke with typically made. Problem with your peas falling over and therefore not growing properly? Build a trellis. Pests getting into your broccoli? Create an exclusion trap. There were no examples of any teachers in my study using engineering design in the garden, though several of them thought engineering would be a natural extension of their science or math-based garden curriculum.

\section{Conclusion}

Even though gardens cost time and support in a variety of shades, a well-utilized garden can help to accomplish a broad span of academic topics while also introducing and strengthening student emotional/psychological aspects. Over the past several decades, there have been many studies that have shown the value of school gardens as learning settings for students and as instructional tools for teachers. With the proper resources, school gardens have the potential to become a valued part of the student body, teaching and administrative faculty, and community as a whole ("The Edible Schoolyard Project, Our History,” n.d.).

Nonetheless, it is evident through this project and published research findings on school gardens that instructional and logistical support constructs must be factored into a garden program in order for it to be accessible. A clear garden plot in and of itself is often not enough to attract sustained use by teachers. Integration of instruction at all grade levels and across multiple subjects naturally creates greater support. However, this grafting doesn't happen organically; like any successful harvest, garden integration takes 
time, knowledge, and care. It is vitally important for school gardens to become part of the culture of a school, where multiple teachers use it in their instruction, and where multiple garden champions cross-pollinate with others to build greater knowledge and support. To reach its ultimate potential for benefitting students, a school garden must be truly valued and utilized as a setting for teaching and learning across all levels.

A school garden is a commitment that needs to be considered in light of both immediate circumstances and long term goals. Unlike some other instructional mediums, a garden needs constant inputs to produce worthwhile outputs; it cannot successfully exist without teamwork. Successful integration, maintenance, and use of a school garden relies on ever-growing positive feedback of care. If a school can put all of these pieces together and lay a foundation for the garden to grow, the enthusiasm of students alone will soon have it thriving. 


\section{References}

A Framework for K-12 Science Education: Practices, Crosscutting Concepts, and Core Ideas. (2013). Retrieved from http://www.nap.edu/catalog/13165/a-frameworkfor-k-12-science-education-practices-crosscutting-concepts

Anderson, D., \& Clark, M. (2011). Development of syntactic subject matter knowledge and pedagogical content knowledge for science by a generalist elementary teacher. Teachers and Teaching, 18(3), 315-330.

Avery, L. M., \& Meyer, D. Z. (2012). Teaching science as science is practiced: Opportunities and limits for enhancing preservice elementary teachers' selfefficacy for science and science teaching. School Science and Mathematics, (7), 395-409.

Blair, D. (2009). The child in the garden: An evaluative review of the benefits of school gardening. Journal of Environmental Education, 40(2), 15-38.

DeMarco, L. W., Relf, D., \& McDaniel, A. (1999). Integrating gardening into the elementary school curriculum. HortTechnology, 9(2), 276-281.

Dyment, J. E. (2005). Green school grounds as sites for outdoor learning: Barriers and opportunities. International Research in Geographical and Environmental Education, 14(1), 28-45.

The Edible Schoolyard Project, Our History. (n.d.). Retrieved from http://edibleschoolyard.org/our-story

Flick, D. L. B. (1993). The meanings of hands-on science. Journal of Science Teacher Education, 4(1), 1-8.

Graham, H., \& Zidenberg-Cherr, S. (2005). California teachers perceive school gardens as an effective nutritional tool to promote healthful eating habits. Journal of the American Dietetic Association, 105(11), 1797-1800.

Jorgenson, S. (2014). The logic of school gardens: A phenomenological study of teacher rationales. Australian Journal of Environmental Education, (2), 121-135.

Kelley, S. S., \& Williams, D. R. (2013). Teacher professional learning communities for sustainability: Supporting STEM in learning gardens in low-income schools. Retrieved from http://pdxscholar.library.pdx.edu/elp_fac/9/

Klemmer, C. D., Waliczek, T. M., \& Zajicek, J. (2005). Growing minds: The effect of a school gardening program on the science achievement of elementary students. Horttechnology, 15(3), 448-452.

Lee, H.-S., \& Butler, N. (2003). Making authentic science accessible to students. International Journal of Science Education, 25(8), 923-948. 
Ozer, E. J. (2007). The effects of school gardens on students and schools:

Conceptualization and considerations for maximizing healthy development. Health Education \& Behavior, 34(6), 846-863.

Ramey-Gassert, L., Shroyer, M. G., \& Staver, J. (1996). A qualitative study of factors influencing science teaching self-efficacy of elementary level teachers. Science Education, 80(3), 283-315.

Ray, J., Wei, K. M., \& Barrett, D. (2010). Effect of experience-based school learning gardens professional development program workshop on teachers' attitudes towards sustainability education. Education, 2010. Retrieved from http://www.jsedimensions.org/wordpress/content/effect-of-experience-basedschool-learning-gardens-professional-development-program-workshop-onteachers-attitudes-towards-sustainability-education_2013_06/

Saxton, E., Burns, R., Holveck, S., Kelley, S., Prince, D., Rigelman, N., \& Skinner, E. A. (2013). A common measurement system for K-12 STEM education: Adopting an educational evaluation methodology that elevates theoretical foundations and systems thinking. Studies in Educational Evaluation.

Smith, L., \& Motsenbocker, C. E. (2005). Impact of hands-on science through school gardening in Louisiana public elementary schools. Horttechnology, 15(3), 439443.

Tschannen - Moran, M., \& Hoy, A. W. (2002). Teacher efficacy: Capturing an elusive construct. Teaching and Teacher Education, 17(7), 783-805.

Van Driel, J. H., Beijaard, D., \& Verloop, N. (2001). Professional development and reform in science education: The role of teachers' practical knowledge. Journal of Research in Science Teaching, 38(2), 137-58.

Williams, D., \& Dixon, P. S. (2013). Impact of garden-based learning on academic outcomes in schools: Synthesis of research between 1990 and 2010. Review of Educational Research, 83(2), 211-235.

Williams, D. R. (2012). Learning gardens and sustainability education bringing life to schools and schools to life. New York: Routledge. 


\section{Appendix A}

\section{P Portland $\underset{\text { NNIVERSITY }}{\text { State }}$}

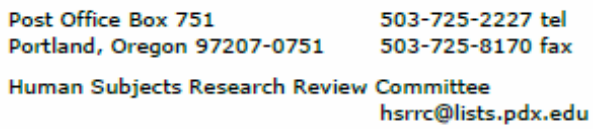

Date: February 17,2015

To: Melissa Potter / Megan Poole

From: Karen Cellarius, HSRRC Chair

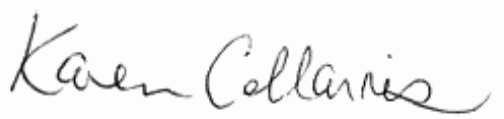

Re: HSRRC approval for your project titled, "The Effects of School Gardens on Elementary Teacher Instruction" HSRRC Proposal \# 153294

Approval-Expiration: February 17,2015 - February 16, 2016

Review Type: Expedited, Categories 6,7

In accordance with your request, the PSU Human Subjects Research Review Committee has reviewed your request for approval of the project referenced above for compliance with PSU and DHHS policies and regulations covering the protection of human subjects. The Committee is satisfied that your provisions for protecting the rights and welfare of all subjects participating in the research are adequate, and your project is approved. Please note the following requirements:

Approval: You are approved to conduct this research study only during the period of approval cited above; and the research must be conducted according to the plans and protocol submitted (approved copy enclosed).

Consent: Signed consent is required from all participants in this study.

Changes to Protocol: Any changes in the proposed study, whether to procedures, survey instruments, consent forms or cover letters, must be outlined and submitted to the Committee immediately. The proposed changes cannot be implemented before they have been reviewed and approved by the Committee.

Continuing Review: This approval will expire on 02/16/2016. It is the investigator's responsibility to ensure that a Contimuing Review Report on the status of the project is submitted to the HSRRC two months before the expiration date, and that approval of the study is kept current. The Contimiing Review Report is available at www.rsp.pdx.edu/compliance human php and in the Office of Research and Strategic Partnerships (RSP).

Adverse Reactions and/or Unanticipated Problems: If any adverse reactions or unanticipated problems occur as a result of this study, you are required to notify the Committee immediately. If the issue is serious, approval may be withdrawn pending an investigation by the Committee.

Completion of Study: Please notify the Committee as soon as your research has been completed. Study records, including protocols and signed consent forms for each participant, must be kept by the investigator in a secure location for three years following completion of the study (or per any requirements specified by the project's funding agency).

If you have questions or concerns, please contact the Office of Research Integrity in the PSU RSP at 503-725-2227. 